\title{
Techno-economic and Environmental Modelling and Optimization of Flexible Distributed Multi- Generation Options
}

\author{
Tomislav Capuder, Pierluigi Mancarella
}

\begin{abstract}
It is arguable how much flexibility and efficiency from coupling different energy vectors through available technologies is exploited in current energy systems. In particular, in spite of the growing interest for the multi-energy concept, there are very few models capable of clearly explaining the benefits that can be derived from integration of complementary technologies such as cogeneration, electric heat pumps and thermal storage. In this light, this paper introduces a comprehensive analysis framework and a relevant unified and synthetic Mixed Integer Linear Programming optimization model suitable for evaluating the techno-economic and environmental characteristics of different Distributed Multi-Generation (DMG) options. Each option's operational performance and flexibility to respond to electricity market signals are analyzed in detail and assessed against the needed investment costs in different contexts. Numerical case studies focus on highlighting the flexibility benefits that can be gained in economic terms from multi-energy system integration in District Heating (DH) applications. Detailed sensitivity analyses of different DMG configurations also clearly show what economic as well as environmental performance (at both global and local levels) can be expected in current and future scenarios when coupling different energy vectors and complementary technologies in a multi-energy context.
\end{abstract}

Keywords — cogeneration, distributed multi-generation, electric heat pumps, flexibility, multi-energy systems, thermal storage.

\section{Nomenclature}

Acronyms and Indices

$\begin{array}{ll}\text { AEF } & \text { Average Emission Factor } \\ \text { CCGT } & \text { Combined Cycle Gas Turbine } \\ \mathrm{CO} & \text { Carbon Monoxide } \\ \mathrm{CO}_{2} & \text { Carbon Dioxide } \\ \mathrm{CHP} & \text { Combined Heat and Power } \\ \mathrm{DH} & \text { District Heating } \\ \mathrm{DMG} & \text { Distributed Multi-Generation } \\ \text { EDS } & \text { Electricity Distribution System } \\ \text { EHP } & \text { Electric Heat Pump } \\ \text { LSP } & \text { Local Separate Production } \\ \text { MILP } & \text { Mixed Integer Linear Programming } \\ \text { MSG } & \text { Minimum Stable Generation } \\ \text { NO } & \text { Nitrogen Oxides } \\ \text { PPES } & \text { Polygeneration Primary Energy Saving } \\ \text { PCO2ER } & \text { Polygeneration CO } \text { Cmission Reduction }_{2} \text { Emion } \\ \text { SP } & \text { Separate Production } \\ \text { D } & \text { Demand } \\ \text { e } & \text { Electricity } \\ \text { t } & \text { Thermal } \\ \text { aux } & \text { Auxiliary } \\ \text { s } & \text { Thermal energy storage } \\ \end{array}$

Tomislav Capuder is with the Faculty of Electrical Engineering and Computing, Energy and Power Systems Department, University of Zagreb, Zagreb, Croatia and visiting researcher with the School of Electrical and Electronic Engineering, Electrical Energy and Power Systems Group, University of Manchester, Manchester, UK (e-mail: tomislav.capuder@manchester.ac.uk, tomislav.capuder@ fer.hr).

Pierluigi Mancarella is with the School of Electrical and Electronic Engineering, Electrical Energy and Power Systems Group, University of Manchester, Manchester, UK (e-mail: p.mancarella@manchester.ac.uk). 


\title{
Input values
}

$\eta_{e}$
$\eta_{t}$
$\alpha$
$C O P$
$E_{D}$
$H_{D}$
$E_{\text {chp_max }}$
$E_{\text {chp_min }}$
$H_{\text {aux_max }}$
$H_{\text {hp_max }}$
$T_{s_{-} \max }$
$T_{S_{\_} \min }$
ramp
$C_{\text {fuel }}$
$C_{\text {elec_buy }}$
$C_{\text {elec_sell }}$

\author{
Electric efficiency of a CHP unit \\ Thermal efficiency of a CHP unit \\ Shifting factor \\ Coefficient of performance \\ Electricity demand \\ Heat demand \\ Maximum generation output of CHP unit \\ Minimum stable generation of CHP unit \\ Maximum boiler output \\ Maximum heat generation from EHP
}

Maximum water temperature in the thermal storage tank

Minimum water temperature in the thermal storage tank

Ramp rate value of the CHP unit

Cost/price of input fuel (natural gas)

Cost/price of electricity bought from the grid

Cost/price of electricity sold to the grid

Decision variables

$E_{c h p}$
$H_{c h p}$
$I_{c h p}$
$H_{s}$
$H_{\text {cux }}$
$H_{h p}$
$E_{h p}$
$E_{h p \_c h p}$
$E_{h p \_g}$

Electricity produced by CHP unit

Heat produced by a CHP unit

Binary variable indicating if the CHP unit is on/off

State of charge of thermal energy storage

Heat produced by auxiliary boiler

Heat produced by EHP

Electricity needed by EHP for heat production

Electricity produced by CHP and used by EHP for heat production

Electricity from the electric grid and used by EHP for heat production

\section{INTRODUCTION}

In the light of the increasing interest for multi-energy systems, where multiple energy vectors optimally interact with each other [1], district energy systems are likely to play a more and more important role in delivering a sustainable energy future, particularly with the projected number of people living in cities constantly increasing. In this outlook, multi-generation options for combined production of different energy vectors [2], [3], [4] are an effective solution to increase energy efficiency, particularly in urban areas and in district energy systems. The simplest multi-generation concept is combined heat and power (CHP), producing usable heat and electricity from a certain input fuel. Advantages of combined heat and power plants, with respect to the conventional separate production (SP) of electricity and heat, are well known [5], [6]. In [7] the author elaborates on basic efficiency concepts determined by the European Directive for the promotion of cogeneration, providing guidelines on defining primary energy savings of CHP units which are eligible for financial benefits. Economic and environmental advantages of CHP units for district heating (DH) systems are analyzed in [8] and [9]. Electric heat pumps (EHP), also considered as an efficient and economic alternative to existing boilers, have a capability to decarbonise the heating sector but are dependent on concurrent decarbonisation of electricity generation. In addition, large integration of EHP means significant increase of electricity load in the grid. This will eventually require further investments in the electric grid infrastructure [10].

Conventional small to medium scale CHP units are negligibly flexible in responding to electricity market prices as they have a primary task of covering demand (of heat or in limited cases of electricity), and in order to be able to cope with more volatile 
Energy, Accepted for publication, 2014

energy prices they need to be more flexible. This is where the importance of coupling with Thermal Energy Storage (TES) is recognized, most noticeably in Denmark where this strategy was initially supported by three level feed-in-tariff; today even smaller distributed units are allowed to participate in the electricity day-ahead market [11]. Several other countries have introduced incentives for wide spread integration of DH CHP systems such as Germany [12]. Sweden has instead decided to focus its heating policy on EHP systems which have already been installed in Stockholm [13]. Despite the primary focus on EHP in Sweden, city of Linköping is also supplied by CHP coupled with TES [14]. The UK is also committed to the decarbonisation of the whole energy sector and heating in particular. In this respect, different strategies have been proposed [15], [16], [17], to follow up on experience and successful implementations of the Danish/Swedish energy policies. Studies researching the optimal size of CHP coupled with TES for the case of DH in the UK are presented in [18], [19]. Today only $2 \%$ of UK consumers are connected to DH systems, but estimates [20] suggest this technology could have a significant share in heat supply for 40 million forecasted UK consumers in 2030.

While benefits enabled by thermal storage are fairly clear, there is less understanding of the potential to couple CHP to EHP (and in case storage too) to gain significant flexibility to respond to system requirements and prices. These systems could have an even greater value in future electricity systems with large share of renewable energy sources when excess electricity can be harvested by shifting between energy vectors [21], [22]. Some papers indeed conclude that combination of technologies could be the optimal solution in coping with volatility of net electricity load caused by increasing share of renewable energy sources [23], but this issue has not been explored systematically as yet. In particular, there are neither experiences nor comprehensive modeling framework and systematic studies on Distributed Multi-Generation (DMG) [24], [25] options, particularly the ones based on combination of CHP and EHP and whose role remains relatively unclear.

This uncertain but very dynamic context thus paves the way to the opportunity of exploring new alternative and innovative DMG options based on CHP and EHP that could be effectively deployed to increase the economic and environmental performance of future DH systems, particularly in the UK. The potential benefits these systems bring are already recognized in different countries [14], [26], [27], and for different district energy system applications [4], [28]. The term "equivalent cogeneration plant" is for instance introduced in [29] exemplifying the benefits of cascading CHP-EHP through energy shifting factors. This concept can provide significant emission reduction [29] as well as primary energy savings, as also shown in [5], [30]. The concept is further expanded to capture the flexibility benefits of multi-generation units in [31], [32]. The idea of CHPEHP where EHP uses cooled stored air from flue gases of CHP as a "free fuel" is presented in [33], [34]. These papers can be considered state-of the art in terms of coupling different units and increasing flexibility by operational shifting between different energy vectors. However, there is no comprehensive market and environmental analysis of such DMG options.

On the above premises, the aim of this work is to define a comprehensive and unified techno-economic and environmental modelling and optimization framework for the operational and planning evaluation of different DMG options for DH systems. The concept of flexibility, seen here from the point of view of operational flexibility (capability to respond to price signals in close to real time), is analysed in detail for the different options. In addition, the different DMG options are also assessed from an investment perspective, also considering different price scenarios, as well as from an environmental perspective considering both local (from local pollution) and global impact (primary energy consumption and $\mathrm{CO}_{2}$ emissions) impact and in different scenarios. In this way, a systematic and comprehensive picture of pros and cons of different DMG options in different contexts will be provided.

The rest of the paper is organized as follows. Section II defines different district heating DMG options and presents a unified MILP market based mathematical model, as well as the relevant and consistent environmental assessment models. Numerical case study examples are elaborated in Section III, exemplifying market driven operation of different options in a realistic UK context. Sensitivity analyses are also run to assess the robustness of the optimal solutions, and investment and environmental analyses further highlight the benefits gained by each DMG option in different conditions. Conclusions and guidelines for future work are presented in Section IV.

\section{TECHNO-ECONOMIC AND ENVIRONMENTAL MODELLING AND OPTIMIZATION FRAMEWORK FOR DH DMG OPTIONS}

\section{A. Description of DH DMG options}

This Section introduces a comprehensive and synthetic modeling framework that, in a unified fashion, can perform description and optimization of all the considered DH DMG options so that like for like studies can be readily performed. For the purpose of systematic techno-economic comparison, this paper defines seven different DH schemes based on DMG options: 
- Type 1: A conventional boiler is considered throughout the paper as a reference case for comparing other proposed DH schemes. A centrally connected boiler produces heat and, through a heat network, supplies consumers. Electricity demand is satisfied through electrical network connection and electricity is produced by the incumbent bulk generation system and is assumed to be purchased on the wholesale market.

- Type 2: A central EHP system provides heat using electricity from the electricity grid. As in the first case, electricity demand is supplied through the electricity grid.

- Type 3: Thermal energy storage (TES) is added here to the scheme proposed in type 2, with the idea of bringing additional flexibility in the heating side.

- Type 4: CHP-AB system. This is the prevailing DH concept with CHP units, where an auxiliary boiler (AB) is utilized only for covering peak heat demand or for back-up. Electricity can be bought from or sold to the electrical grid.

- Type 5: CHP-AB-TES system. Thermal storage here provides flexibility to the CHP unit, enabling it to decouple its operation from heat demand following.

- Type 6: CHP-AB-EHP system. An EHP unit is cascaded to CHP. The inherent flexibility of supplying electricity and heat from different inputs in principle significantly increases responsiveness to price signals and variable demand.

- Type 7: CHP-AB-EHP-TES system. This scheme combines the benefits of the previous two types cascading CHP with a TES and EHP, gaining additional flexibility.

The relevant energy flow layout of all defined DMG types is presented in Fig. 1.
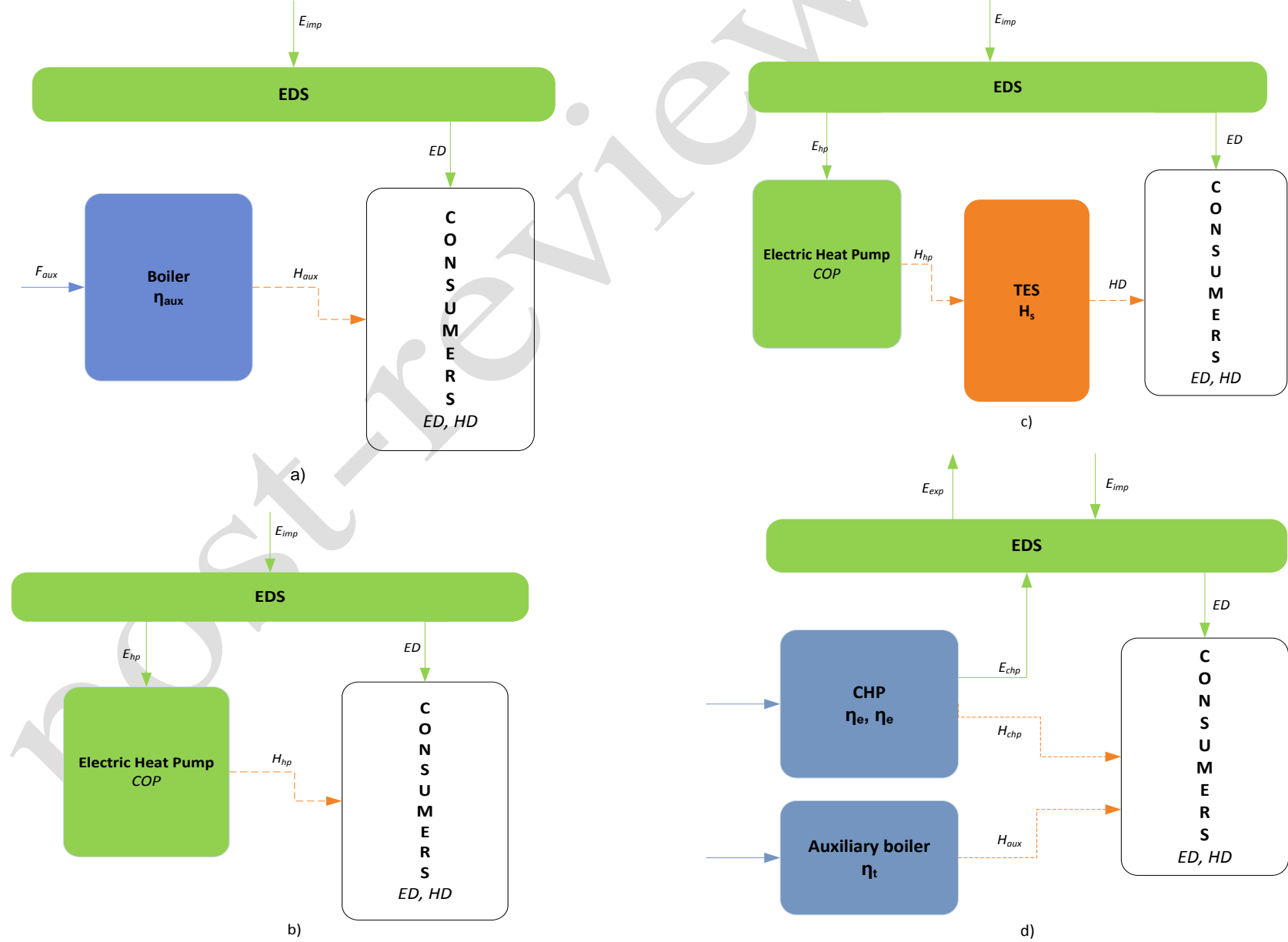

c)

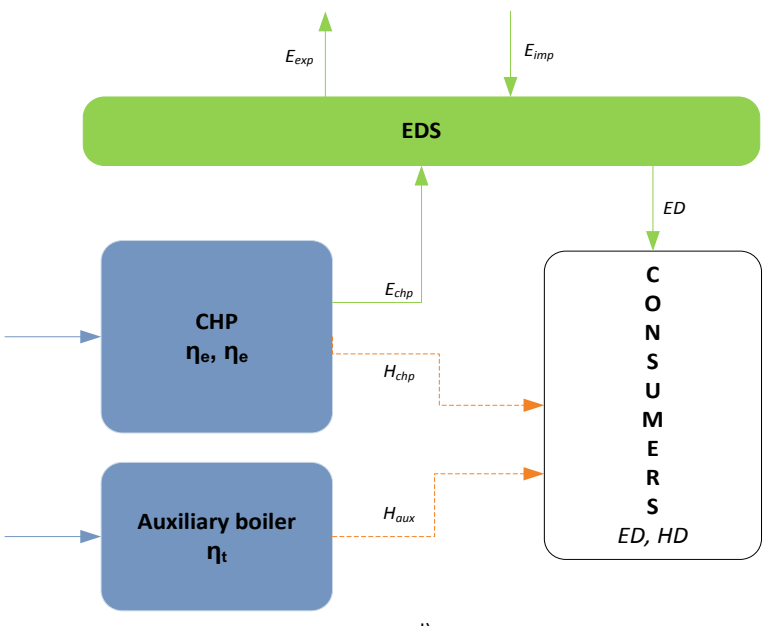

d) 


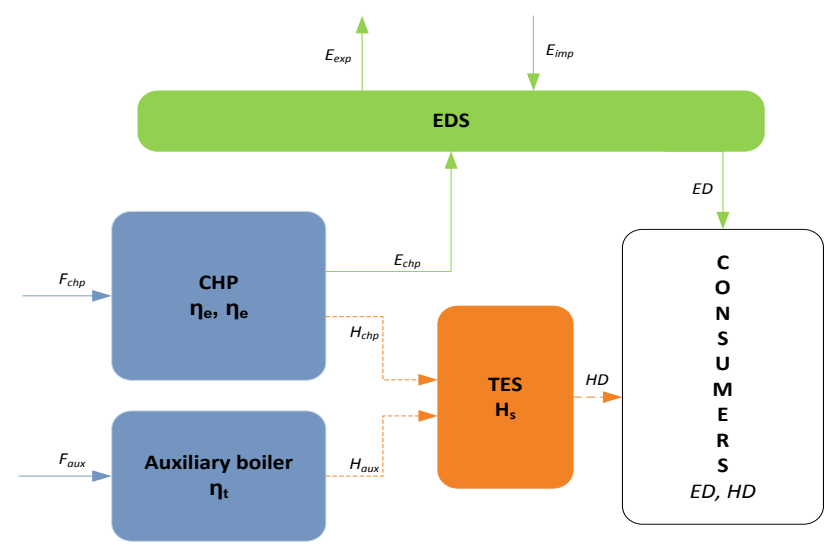

e)

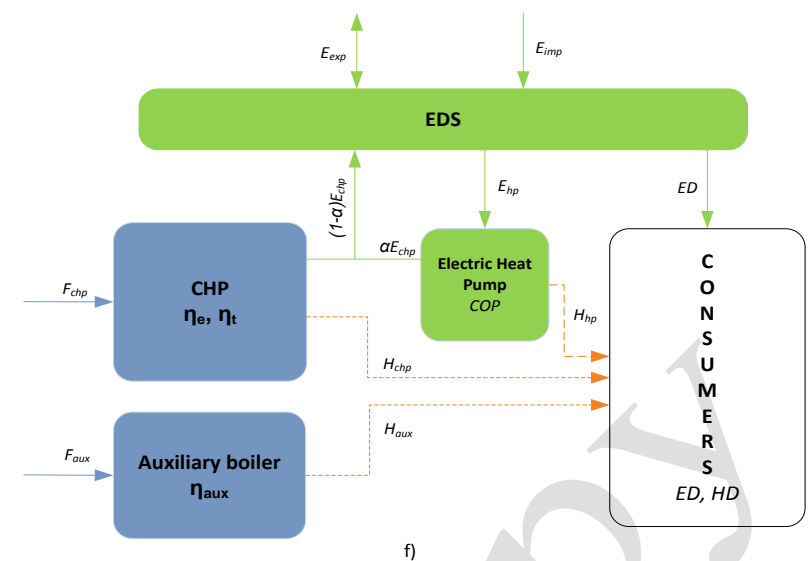

f)

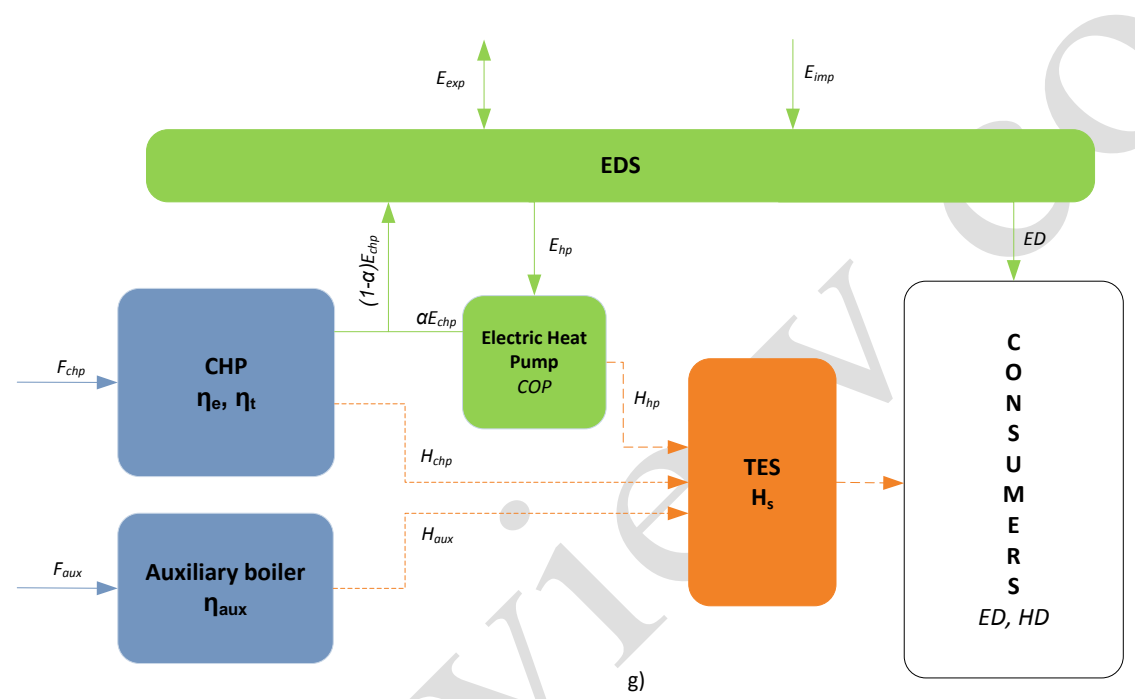

Fig. 1. Energy flow layout of a) DMG type 1, b) DMG type 2, c) DMG type 3, d) DMG type 4, e) DMG type 5, f) DMG type 6, g) DMG type 7

\section{B. Unified mathematical formulation of the DMG DH modelling and optimization problem}

\section{B.1 Problem and modelling background discussion}

Mathematical models describing CHP short term operation go back to Püttgen et al. [35], [36]. An interesting approach using mixed-integer formulations describing operation of large back steam pressure CHP units with feasible generation region can be found in [37] and [38]. In [39] the authors present a conceptual approach to modelling each grid user in a unified way as power nodes, consisting of its belonging efficiencies, losses, demand and generation, covering all electro-chemical conversions. The concept of power nodes is a unified way of presenting a single consumer/producer/storage and its interaction with the grid. However, there is no market-driven or other type of optimization developed in the model. A complete overview on short-term operational modelling of CHP units can be found in [40] giving an understanding on different operational limits and technical constraints. Recent focus has been turned to smaller distributed generation CHP units as they are becoming a relevant factor in electricity markets; for instance, in [41] the authors present a mathematical model for $\mu$ CHP unit coupled with TES, comparing different operating scenarios for fuel cells. In [42] the authors propose a mathematical model for economic evaluation to supply electricity, heating and cooling load to a food factory by coupling CHP and EHP. Mehleri et al present a mathematical modelling approach to planning the entire district energy system taking into account the investment and the operation cost of different technologies [43]. However, the model relies on fixed grid prices and fixed feed-in tariffs for PV and $\mu$ CHP and thus the operation of each unit (and the entire microgrid) is implicitly led by demand and does not exploit potential flexibility. In [44] the authors propose a mathematical formulation for a single $\mu$ CHP unit and a cluster of $\mu$ CHP units, each with its own thermal storage decoupling demand and production, enabling each unit to be more flexible and have lower operational cost. Further flexibility in the considered microgrid is also provided by a centralized TES unit. However, there is no consideration of EHPs. An interesting approach that synthesizes different pieces of equipment with the goal of finding optimal superstructure of power 
plant types, auxiliary equipment, and heat networks is described in [45], [46]. The concept of superstructure is applied for the design of trigeneration system in [47]. The same group of authors previously worked on the optimal trigeneration system design using evolutionary algorithm component based modelling [48]. However, none of these papers elaborates on the operational flexibility which can be gained by adding or replacing a certain piece of equipment. Also, there is a lack of comprehensive investment studies as well as environmental impact studies.

From the systematic literature review analysis that was carried out, it emerges that all the models currently available are either case specific or lack methodical assessment of the marginal effect of equipment addition/substitution. Further none can represent comprehensively and consistently different DMG options including CHP, EHP and TES, and their flexibility in terms of operational optimization. Additionally there is no unified approach to operational, investment and environmental assessment. On the contrary, the developed MILP model discussed in the following Section is capable of capturing the optimal operation of all the DMG types presented above, namely types $2-7$, and this is done by developing a synthetic problem formulation that entails all the considered options in a unified way. Figure 2 illustrates through a flow chart the idea of how each DMG type can be "created" by combining different pieces of equipment. More specifically, while DMG type 2 and DMG type 4 are a single "generation" unit types, composed only of EHP (type 2) or CHP (type 4), all remaining DMG types are structured as cascades of either or both of these units along with storage. From the figure, it can also be appreciated how DMG type 7 is the most complex one and all other DMG types can be considered as subtypes of type 7.

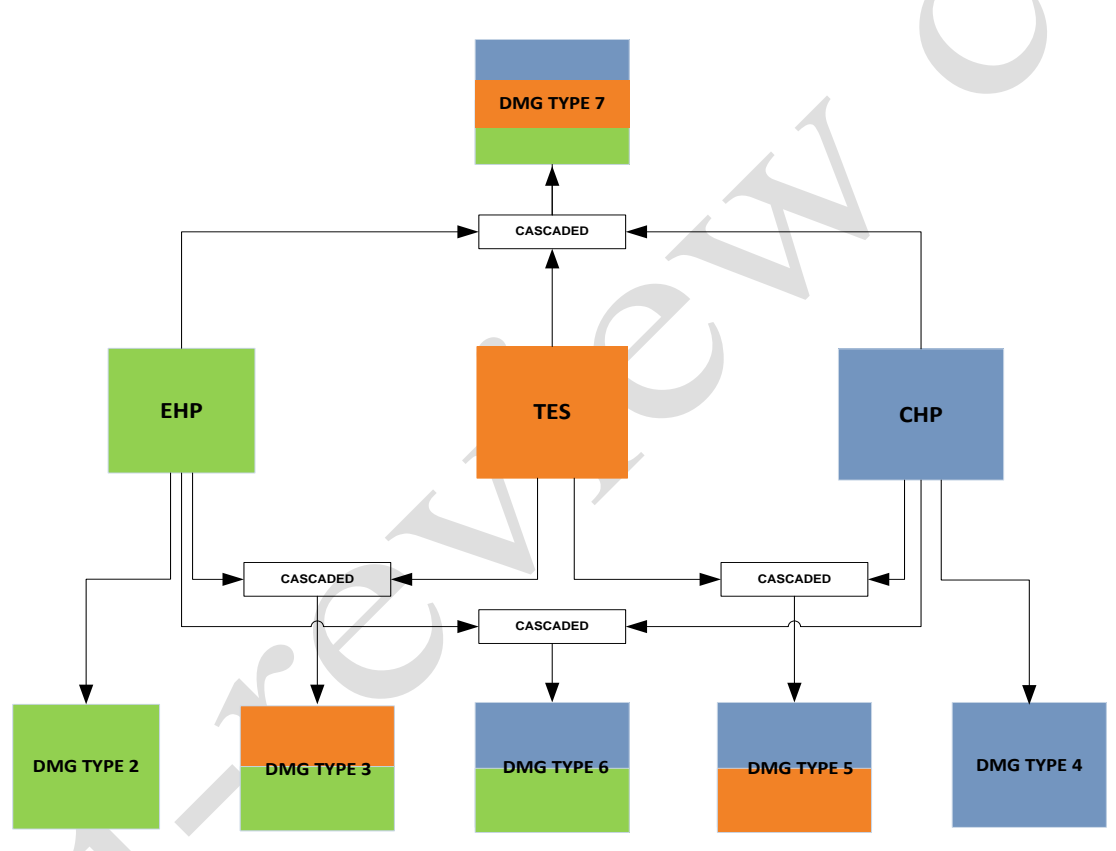

Fig.2. DMG types creation flow diagram

\section{B.2 Operational optimization problem formulation}

The general operational optimization problem under analysis here can be stated as

$$
\text { minimize OPERATIONAL_COST }=\sum_{t=1}^{T}\left[C_{\text {fuel }}(t)+C_{\text {elec_buy }}(t)-C_{\text {elec_sell }}(t)\right]
$$

Equation (1) contains the objective function to minimize, that is, the operational cost for each of DMG units taking into account fuel and electricity prices for each components of the specific option (CHP, EHP, boiler, TES). The objective function is oriented towards assessing economic benefits and does not include Operation and Maintenance cost (O\&M) in order to better highlight the economic performance of the different options based on energy prices. However, O\&M can be easily incorporated in the framework.

In terms of problem constraints, starting from the flow chart in Figure 2, in the following all constraint equations for each and all DMG types are formulated in a unified and comprehensive way by making use of a suitable superscript notation. More specifically, a superscript from 2 to 7 in each parameter or variable of the relevant constraint equation indicates that the relevant item exists only in that DMG type associated to the specific superscript number. 
Considering CHP modelling first, the CHP electricity output $E_{c h p}$ and heat output $H_{c h p}$ are defined at each time step starting from the fuel input $F_{c h p}$ through relevant electrical and thermal efficiency functions (superscripts in these equations indicate the CHP can be found only in DMG types 4, 5, 6 and 7). More specifically, in order to represent the CHP plant performance dependency on its operational point, electrical and thermal efficiency curves as from manufacturers' catalogues [49] have been approximated by linear relationships between outputs and fuel input, thus preserving linearity of the entire optimization problem. For this purpose, if we indicate with $I_{c h p}$ a binary decision variable that takes the value of 1 when the CHP unit is on and 0 when the CHP unit is off, the electricity and heat outputs with respect to fuel inputs can be represented as in Eqs. (2) and (3), respectively:

$$
\begin{aligned}
& E_{c h p}(t)^{4,5,6,7}=F_{c h p}(t)^{4,5,6,7} * \eta_{e 1}(t)^{4,5,6,7}+I_{c h p}(t)^{4,5,6,7} * \eta_{e 2}(t)^{4,5,6,7} \\
& H_{c h p}(t)^{4,5,6,7}=F_{c h p}(t)^{4,5,6,7} * \eta_{t 1}(t)^{4,5,6,7}+I_{c h p}(t)^{4,5,6,7} * \eta_{t 2}(t)^{4,5,6,7}
\end{aligned}
$$

where the coefficients $\eta_{e l}$ and $\eta_{e 2}$ are calculated as $f\left(E_{c h p_{-} \min }, E_{c h p_{-} \text {max }}, \eta_{e}\right)$ and $\eta_{t 1}$ and $\eta_{t 2}$ are calculated as $f\left(E_{c h p_{-} \min }, E_{c h p_{-} \max }, \eta_{t}\right)$ from interpolation of manufacturers' curves of efficiency with respect to loading level and considering the full-load electrical efficiency $\eta_{e}$ and thermal efficiency $\eta_{t}$. Numerical values of these coefficients for different CHP units are further illustrated in Table I with reference to the case study example.

In terms of CHP operational constraints, as mentioned earlier the CHP electricity output is limited by its upper limit $E_{\text {chp_max }}$ (maximum power) and by its lower limit $E_{\text {chp_min }}$ (also called Minimum Stable Generation - MSG), which can be expressed as:

$$
I_{c h p}(t)^{4,5,6,7} * E_{c h p \_ \text {min }} \leq E_{c h p}(t)^{4,5,6,7} \leq I_{c h p}(t)^{4,5,6,7} * E_{c h p_{-} \max }
$$

Since thermal power plants typically exhibit specific power variation limits (indicated here as ramp), the power output increase or decrease between two successive time periods are subject to the following constraint:

$$
-\operatorname{ramp} \leq E_{c h p}(t)^{4,5,6,7}-E_{c h p}(t-1)^{4,5,6,7} \leq \operatorname{ramp}
$$

The electric heat pump is present in the DMG types 2, 3,6 and 7, in the latter two cases being cascaded to the CHP unit. At each time step, Eq. (6) describes the relationship between heat output $H_{h p}$ and electricity input $E_{h p}$ through the relevant Coefficient of Performance (COP) value, while Eq. (7) indicate the relevant heat production constraints between the upper limit $H_{h p \_m a x}$ and the lower limit considered here equal to zero:

$$
\begin{gathered}
H_{h p}(t)^{2,3,6,7}=E_{h p}(t)^{2,3,6,7} * C O P(t)^{2,3,6,7} \\
0 \leq H_{h p}(t)^{2,3,6,7} \leq H_{h p_{-} \max }
\end{gathered}
$$

The electricity $E_{h p}$ used for running the EHP is generally composed of two components, namely, an electricity flow coming from the electrical grid $\left(E_{h p_{-}}\right)$and, only in those cases when the EHP is coupled to the CHP unit (that is, DMG type 6 and 7), an electricity flow coming from the CHP $\left(E_{h p_{-} c h p}\right)$. This electricity balance at the EHP input can therefore be written as:

$$
E_{h p}(t)^{2,3,6,7}=E_{h p_{-} c h p}(t)^{6,7}+E_{h p_{-} g}(t)^{2,3,6,7}
$$

Superscripts in (8) denote how the grid is a source of electricity for the EHP in all four types 2, 3, 6 and 7 and also how in types 6 and 7 the CHP represents a further EHP electricity source. Hence, in DMG types 6 and 7 the amount of EHP electricity input coming respectively from the grid and the CHP unit is a result of the optimisation problem. This is highlighted by introducing what can be called shifting factor $\alpha(t)$ [29] which describes the per unit fraction of electricity produced by the CHP unit going to supply the EHP. Graphically this input-output electricity relationship between CHP and EHP is shown in Figure 1 e) and mathematically it is formulated as:

$$
E_{h p_{-} c h p}(t)^{6,7}=E_{c h p}(t)^{6,7} * \alpha(t)^{6,7}
$$


The general overall electricity balance is shown in Eq. (10), which can be viewed as the Kirchhoff nodal law: the sum of all electricity produced locally, consumed locally, and exchanged with the grid needs to be zero:

$$
E_{D}(t)^{2,3,4,5,6,7}=\left(1-\alpha(t)^{6,7}\right) * E_{c h p}(t)^{4,5,6,7}+E_{\text {imp }}(t)^{2,3,4,5,6,7}-E_{\text {exp }}(t)^{4,5,6,7}-E_{h p_{-} g}(t)^{2,3,6,7}
$$

In particular, from (10) it is clear how in the DMG cases 6 and 7, when the EHP is cascaded to CHP, the fraction of electricity produced by the CHP that does not supply the EHP, namely, $(1-\alpha(t)) E_{c h p}$, is either consumed locally as $E_{D}$ or is sold to the market as $E_{\text {exp }}$. The potential electricity amounts $E_{i m p}$ and $E_{h p \_g}$ bought from the market make up the final balance. The electricity balance for cases 2-5 can be explained similarly.

It is interesting to point out how, similarly to the other relationships discussed in this problem formulation but even more evidently, Eq. (10) actually turns into a different equation for each different DMG type, as each of the seven types has different "consumers" (EHP and local demand) and "producers" (CHP and the grid) of electricity. With Figure 2 in mind, this is once again shown by superscripts 2-7: only when a superscript is associated with an existing component for the specific DMG type under consideration can the relevant decision variable take values different from 0 .

With respect to provision of sufficient thermal energy to the customer, in each DMG type an auxiliary boiler exists as backup and to cover peak heat demand, also providing additional operational flexibility in the different cases. The auxiliary boiler's operation is described by Eqs. (11) and (12), showing the relationship between the boiler heat output $H_{\text {aux }}$ and the relevant fuel thermal energy input $F_{\text {aux }}$ through the boiler efficiency $\eta_{\text {aux }}$, as well as the operational constraints between 0 (assumed here to be the lower limit) and the boiler capacity $H_{\text {aux_max }}$, respectively:

$$
\begin{gathered}
H_{\text {aux }}(t)^{2,3,4,5,6,7}=\eta_{\text {aux }}(t)^{2,3,4,5,6,7} * F_{\text {aux }}(t)^{2,3,4,5,6,7} \\
0 \leq H_{\text {aux }}(t)^{2,3,4,5,6,7} \leq H_{\text {aux_max }}
\end{gathered}
$$

Eq. (13) expresses the nodal heat balance in a similar way to the electrical balance in (10), also capturing the inter-temporal operational characteristics of thermal storage. The total thermal energy $H_{s}$ available in the storage at each time step is in fact equal to the stored thermal energy in the previous step plus the net heat input in the observed time step. This net input to the storage system is represented by the sum of the heat production from CHP $\left(H_{c h p}\right)$, auxiliary boiler $\left(H_{\text {aux }}\right)$, and heat pump $\left(H_{h p}\right)$, minus the heat demand $H_{D}$. For the sake of simplicity, storage losses are neglected here (they would be very small considering the size of the system), although again they could be easily incorporated in the model.

$$
H_{s}(t)^{3,4,7}=H_{s}(t-1)^{3,4,7}+H_{c h p}(t)^{4,5,6,7}+H_{\text {aux }}(t)^{2,3,4,5,6,6}+H_{h p}(t)^{2,3,6,7}-H_{D}(t)^{2,3,4,5,5,6,7}
$$

The thermal storage capacity is defined with its hot water temperature $T_{s}$ as a control variable, with operational constraints in the storage tank between $T_{s_{-} \min }=50^{\circ} \mathrm{C}$ and $T_{s_{-} \max }=90^{\circ} \mathrm{C}$. This is described by (14):

$$
T_{s_{-} \min } \leq T_{s}(t)^{3,4,7} \leq T_{s_{-} \max }
$$

The output water temperature of the electric heat pump could in principle be lower than the one from the CHP and additional heating could be needed to reach the output temperature of the CHP; however, here it is assumed that $\mathrm{CO}_{2}$ based EHP are used, whose output temperatures are consistent with the CHP ones. ${ }^{1}$

Once again, it is worth highlighting how the problem equations were all synthetically written according to the superscript-based notation that was mentioned above, whereby specific equations for each specific DMG type are selected from the general constraint "set" by considering the relevant superscript. By doing so, all proposed DMG options (that encompass all the possible $\mathrm{CHP} / \mathrm{EHP} / \mathrm{TES}$ schemes) have been presented under a unified and comprehensive formulation.

\footnotetext{
${ }^{1}$ Research on $\mathrm{CO}_{2}$ heat pump heat systems suggest that the outlet temperature could have above $85^{\circ} \mathrm{C}$ making additional heating unnecessary [77].
} 


\section{Environmental models}

\section{C.1 Primary energy saving}

Combined heat and power generation can bring substantial primary energy and environmental savings compared to separate production [5], [50]. More generally, the multi-generation energy efficiency in terms of primary energy saving can be evaluated through static indicators comparing the energy produced by DMG units to that produced by SP [51], [52]. If expressed with reference to the fuel thermal input for SP, the energy efficiency indicator for CHP systems is the well-known Primary Energy Saving or Fuel Energy Savings Ratio [53]. For a generic multi-generation system this factor is defined as Poly-Generation Primary Energy Savings (PPES) [52]:

$$
P P E S=\frac{F^{S P}-F^{D M G}}{F^{S P}}=1-\frac{F^{D M G}}{\sum_{(X, x) \in D} \frac{X^{D M G}}{\eta_{x}^{S P}}}
$$

$D$ is a set of different demand vectors (electricity and heat, in this case), $F^{S P}$ is the fuel consumed in the separate production needed to comply with the same energy demand as in the multi-generation system. $F^{D M G}$ is the primary energy input to a specific multi-generation option (in these studies all types except type one that is the reference case), including fuel for CHP and boilers; $X^{D M G}$ represents the output value of each energy vector (electricity or heat). The coefficients $\eta_{x}^{S P}$ represent efficiency of separate production for each energy vector. These values are taken as reference to evaluate the primary energy necessary to produce the same amount of energy as in a DMG plant through conventional SP means, as exemplified in Section III.F.

\section{C.2 $\mathrm{CO}_{2}$ emission reduction}

Similarly to primary energy saving, multi-energy systems have the potential to bring $\mathrm{CO}_{2}$ emission reduction with respect to the SP means. However, this crucially depends on the overall system carbon emissions. This issue is even more emphasised in highly fossil fuel based system such as the current UK one. In the environmental assessment of different DMG options conducted here, the electricity produced in a DMG unit (locally consumed or exported) is treated as displacing electricity production from centralized power generation. The input values needed to evaluate the $\mathrm{CO}_{2}$ emissions from each of the DMG option are the DMG fuel (gas) emission intensity, the emission factor of the heat SP, and the Average Emission Factor (AEF) of the electricity grid for each period of unit operation. In particular, a PCO2ER indicator can be defined consistently with the PPES indicator as [52]:

$$
P C O 2 E R=\frac{\left(m_{C O 2}^{F}\right)^{S P}-\left(m_{C O 2}^{F}\right)^{D M G}}{\left(m_{\mathrm{CO} 2}^{F}\right)^{S P}}=1-\frac{\left(\mu_{\mathrm{CO} 2}^{F}\right)^{D M G} * F^{D M G}}{\sum_{(X, x) \in D}\left(\mu_{\mathrm{CO} 2}^{X}\right)^{S P} * X^{D M G}}
$$

Where $m_{\mathrm{CO} 2}^{x}$ is the mass of $\mathrm{CO}_{2}$ emitted to produce the useful energy output $X$ and $\mu_{\mathrm{CO} 2}^{x}$ is the emission factor associated to the production of $X$, expressed in $(\mathrm{g} / \mathrm{kWh})$ [52]. A detailed $\mathrm{CO}_{2}$ emission saving analysis, together with the explanations and values used for the different emission factors, are elaborated in Section III G.

\section{C.3 Local emission reduction}

While energy efficient technologies may have a lower global environmental impact in terms of primary energy and $\mathrm{CO}_{2}$ emissions with respect to SP, local air quality could be worsened due to the emissions of polluting by-products from burning fossil fuels in distributed cogeneration. Typical primary pollutants that are considered in the studies are nitrogen oxides $\left(\mathrm{NO}_{\mathrm{x}}\right)$, carbon monoxide (CO), and volatile organic compounds (VOCs - unburned, non-methane hydrocarbons). Other pollutants, such as oxides of sulphur $\left(\mathrm{SO}_{\mathrm{x}}\right)$ and particulate matter $(\mathrm{PM})$ are mostly dependent on the fuel used and negligible if considering natural gas [53]. This issue will be additionally emphasised in urban areas since these are typically characterized by high concentrations of such pollutants due to traffic pollution. The local air quality regulation could thus often be quite stringent, leading to limited acceptance of DMG systems within densely populated areas. A systematic analysis of these issues for CHP systems have been performed in [54], [55] and it is generalised here to the different DMG options. The local emission values (focusing on $\mathrm{NO}_{\mathrm{x}}$ and $\mathrm{CO}$ for the sake of simplicity) are calculated using (18): 


$$
m_{N O x, C O}^{D M G}=m_{N O x, C O}^{H, S P}+m_{N O x, C O}^{E, C H P}=\mu_{N O x, C O}^{F, S P} * F_{A B} * \eta_{A B}+\mu_{N O x, C O}^{F, C H P} * F_{c h p} * \eta_{e}
$$

This model is relevant to the local emission balance approach discussed in [54], where the emission impact from central generation electricity (both consumed and displaced) is not accounted for since it is considered "far enough" from where the receptors in urban areas are.

\section{NUMERICAL APPLICATIONS}

\section{A. Case study description and equipment sizing}

Case study applications have been performed to illustrate and test the model developed and to compare the different options. For the sake of example, unit sizes are optimized to supply about 1000 consumers of different consumption profiles [56], although the model is general so as to cover any application. Equipment sizing is a result of sensitivity analyses performed for each type and will be discussed below. However, the results for the base case are already presented in Table I for easier understanding of the following discussions. For the EHP, a $\mathrm{CO}_{2}$-based ground-source or water-source heat pump is taken as a reference for centralised applications [57], while for the CHP system a conventional gas-fired internal combustion engine is used. Although CHP units of different sizes could have different nominal performance, same full-load efficiencies have been assumed here for different sizes in order to focus on the comparison in terms of sizing and flexibility for the various DMG options. On the other hand, in order to preserve the same CHP efficiency curve shape with respect to part-load operation between full capacity and MSG, the coefficients $\eta_{e 2}$ and $\eta_{t 2}$ are different for different CHP sizes, as can be appreciated from Table I. For all DMG types, the presence of a $6 \mathrm{MW}$ backup boiler is assumed but it is not considered in the comparison. For the investment and operation analyses CHP sizes of up to about $5 \mathrm{MW}_{\mathrm{t}}$ were considered. The same scale was used for EHP. For all CHP systems, MSG is considered equal to $30 \%$ of full capacity, while no minimum operational level is considered for other equipment.

TABLE I

OPTIMAL SIZES AND RELEVANT EFFICIENCIES OF UNITS FOR DIFFERENT DMG DH SCHEMES

\begin{tabular}{|l|c|c|c|c|c|c|c|}
\hline & TYPE 1 & TYPE 2 & TYPE 3 & TYPE 4 & TYPE 5 & TYPE 6 & TYPE 7 \\
\hline CHP $\left(\mathrm{kW}_{\mathrm{e}}\right)$ & - & - & - & 4000 & 3000 & 2500 & 2000 \\
\hline $\begin{array}{l}\text { Electrical efficiency } \\
\text { full capacity) }\end{array}$ & & & & 0.37 & 0.37 & 0.37 & 0.37 \\
\hline Coefficient $\eta_{e l}$ & & & & 0.4073 & 0.4073 & 0.4073 & 0.4073 \\
\hline Coefficient $\eta_{e 2}$ & & & & -315.412 & -236.559 & -197.133 & -157.706 \\
\hline $\begin{array}{l}\text { Thermal efficiency } \\
\text { full capacity) }\end{array}$ & & & & 0.47 & 0.47 & 0.47 & 0.47 \\
\hline Coefficient $\eta_{t 1}$ & & & & 0.515 & 0.515 & 0.515 & 0.515 \\
\hline Coefficient $\eta_{t 2}$ & & & & -399.891 & -310.067 & -249.594 & -197.417 \\
\hline Boiler $(\mathrm{kW})$ & 6000 & 6000 & 6000 & 6000 & 6000 & 6000 & 6000 \\
\hline Boiler efficiency & 0.85 & 0.85 & 0.85 & 0.85 & 0.85 & 0.85 \\
\hline TES $\left(\mathrm{m}^{3}\right)$ & - & - & 200 & - & 250 & - & 0.85 \\
\hline EHP $(\mathrm{kW})$ & - & 5000 & 3000 & - & - & 2000 & 2000 \\
\hline$C O P$ & - & 3.0 & 3.0 & - & - & 3.0 & 3.0 \\
\hline
\end{tabular}

\section{B. Daily operational analysis}

Operational simulations for each DMG option have been conducted for typical winter, spring, summer, and autumn days to describe representative performance throughout the year. Operation is optimized based on available day-ahead market hourly electricity prices and for given fuel prices (natural gas is assumed here to be input fuel for CHP units). The electricity prices are taken from [58] and electricity and heat profiles from [56]. Gas prices are an average of recent gas prices for power producers in UK taken from [59]. In this paper, for the sake of simplicity perfect forecast of loads and knowledge of energy prices are assumed. 


\section{1) Winter}

In Fig. 3 electricity and heat profiles for a winter day are shown together with the corresponding electricity prices.
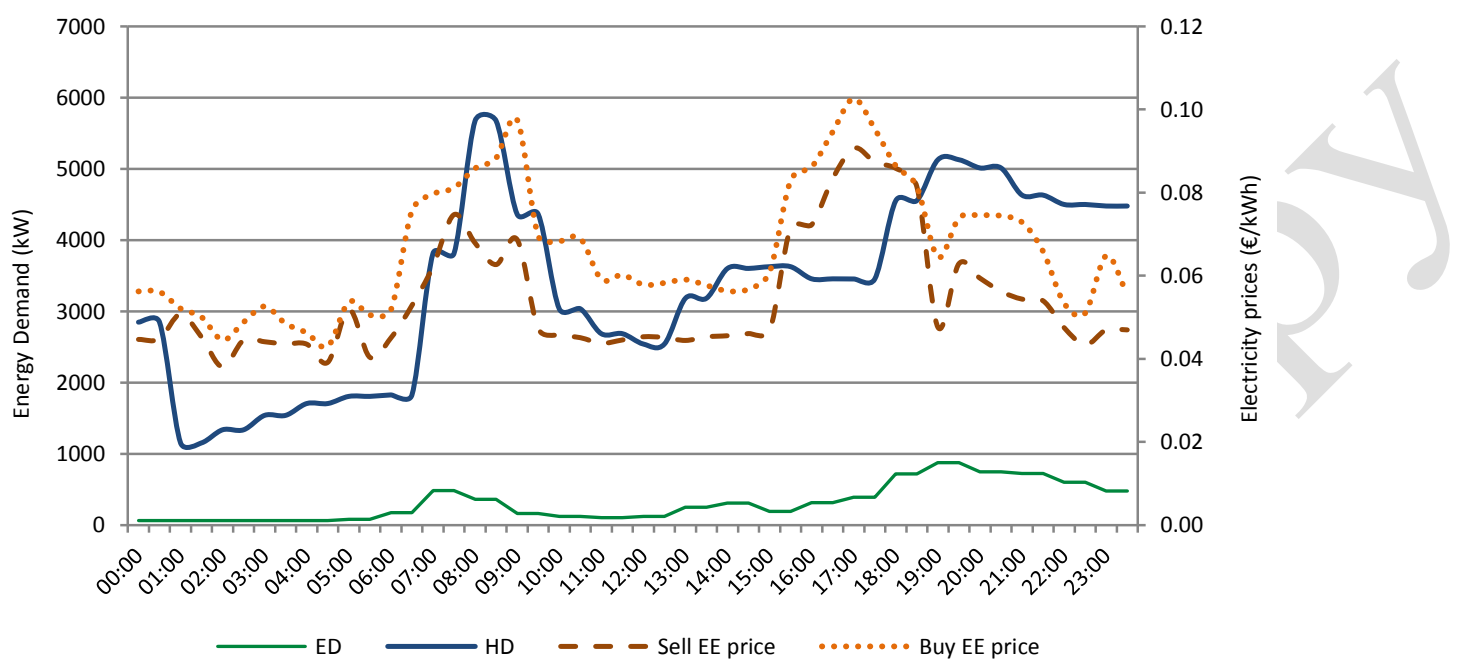

Fig. 3. Demand profiles and electricity prices for a specific winter day

Fig. 4 shows the operation of the CHP-AB (DMG type 4) option. The auxiliary boiler covers around $20 \%$ of annual heat consumption as suggested in [50], [60]. It should be noticed that these numbers come from practical experiences from installing DH systems. When compared to [34], [61] it can be noticed that some previous research did not rely on these experiences which sometimes resulted in over sizing units. These CHP schemes have very limited flexibility as already reported in [62]; they behave as large boilers following heat demand and selling excess electricity (as a "by-product") to the grid.
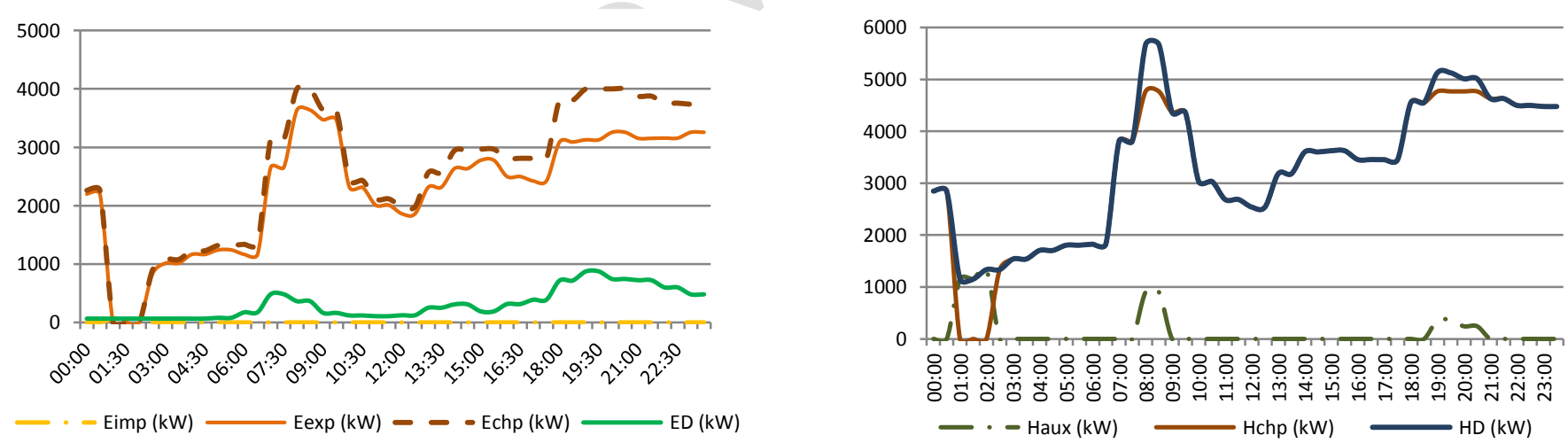

Fig. 4. Daily operation of DMG type 4 for a typical winter day - electricity and heat

Coupling thermal storage to CHP and AB units creates flexibility (DMG type 5). In this case, the CHP unit is not solely driven by the consumers' heat demand, as it is able to store excess heat during high electricity prices and thus sell electricity at favourable market prices. On the other hand, during periods of low electricity prices the CHP can be offline and the heat demand can be covered by the $\mathrm{AB}$ and TES. Coupling cogeneration and thermal storage has therefore the potential to provide demand response since flexibility arises from shifting between different energy vectors responding to real-time prices without reducing consumers' comfort [63]. Fig. 5 presents the daily operation of this scheme for a typical winter day. The mentioned flexibility can be seen in the early morning hours (2:00-5:00) where the spark spread between electricity and gas (difference between the electricity price and the gas price adjusted by the electrical efficiency) is unfavourable for CHP to be operational. In this period, a part of heat demand is covered by discharging the thermal storage, while electricity is bought from the market. On the other hand, in the periods 10:00-14:00 when electricity prices are high, the CHP operates at its maximum storing excess heat in the 
TES.
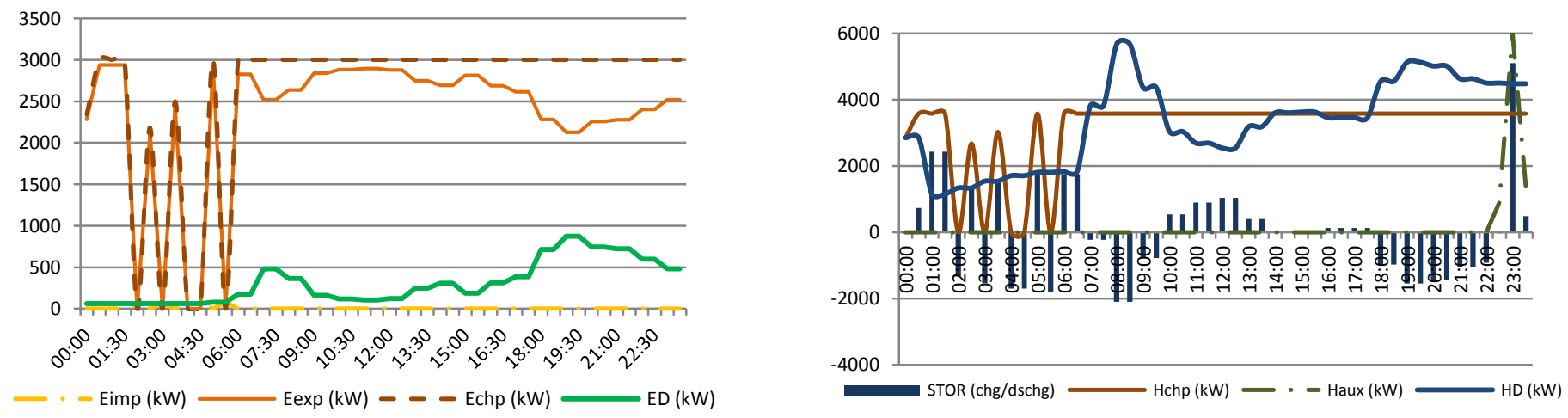

Fig. 5. Daily operation of DMG type 5 for a typical winter day - electricity and heat

Cascading CHP and EHP creates virtual competition between these two units based on the hourly spark spread. The heat pump can be supplied either from the CHP or from the grid, while CHP production is not strictly dictated by heat demand, thus leading to more profit-oriented operation. This competition can be clearly seen during the afternoon periods, between 14:00-22:00, in Fig. 6. In these periods the heat pump uses electricity produced by CHP instead of grid electricity minimizing the overall operational cost. An interesting sag in the exported (sold) electricity can be noticed at the period 8:00-9:00 when, despite high electricity price on the market, the heat peak demand drives the utilization of the heat pump. In general, in fact, high market prices of import electricity mean it is more feasible for the EHP to use electricity produced by CHP to cover the consumers' heat demand. However, although the flexibility in this DMG configuration is increased relative to previous cases, during peak heat demand the DMG system still tends to be driven by demand rather than by market price signals. This suggests that electricityheat coupling is only partially buffered in this scheme (at least at peak consumption times).
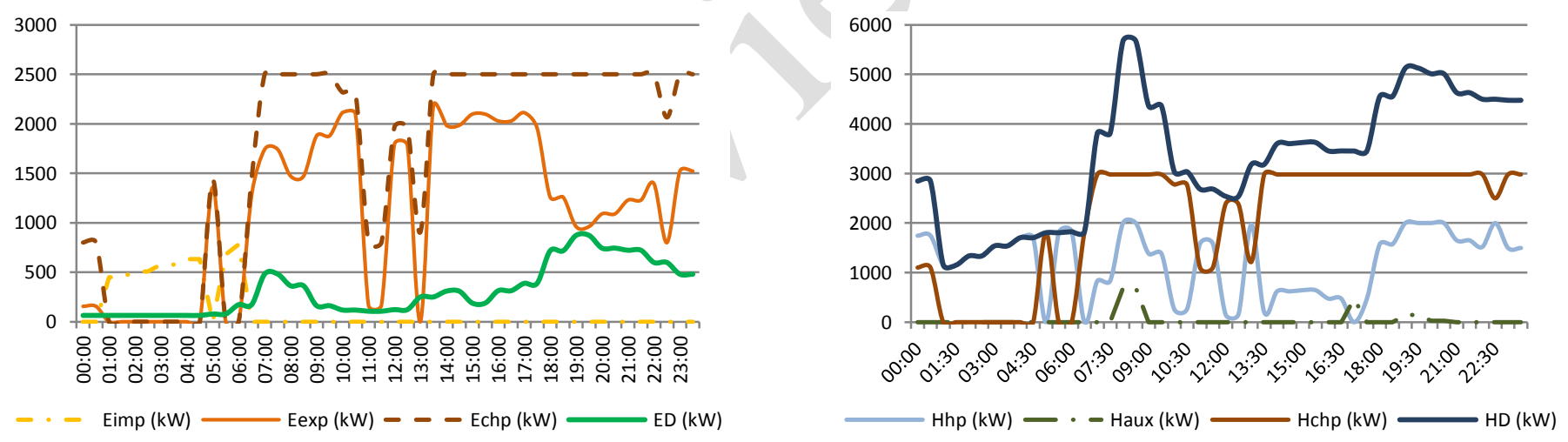

Fig. 6. Daily operation of DMG type 6 for a typical winter day - electricity and heat

Following up on the conclusions of the previous paragraph, it can be appreciated that addition of thermal storage to the CHPEHP cascade creates a more flexible DMG unit primarily driven by market signals (DMG type 7). Now both units optimize their operation based on the electricity prices but also based on the state of charge of TES. This can be seen during the periods 7:00 10:00 in Fig. 7. High electricity prices push the CHP to operate at its maximum. However, the heat produced by CHP is not sufficient to cover the entire heat demand. Comparing the same periods for operations of DMG type 6 and 7 it can be noticed that in the mentioned period the EHP is used to cover the remaining heat demand. Since the price of electricity is high during this period, in DMG type 7 the TES is instead discharged and thus lower overall operational costs are achieved. Comparing the periods between 11:30 and 12.30 for DMG type 6 and DMG type 7, the benefits from adding TES become apparent. Addition of thermal storage enables the CHP system to produce maximum output exploiting the benefits of high market prices, since the TES enables it to store excess produce heat. In contrast, in DMG 6 (without TES) CHP and EHP are following the heat demand having the EHP being utilized almost at its maximum. The flexibility benefits obtained in these periods reflect in operational savings of the last DMG option. 

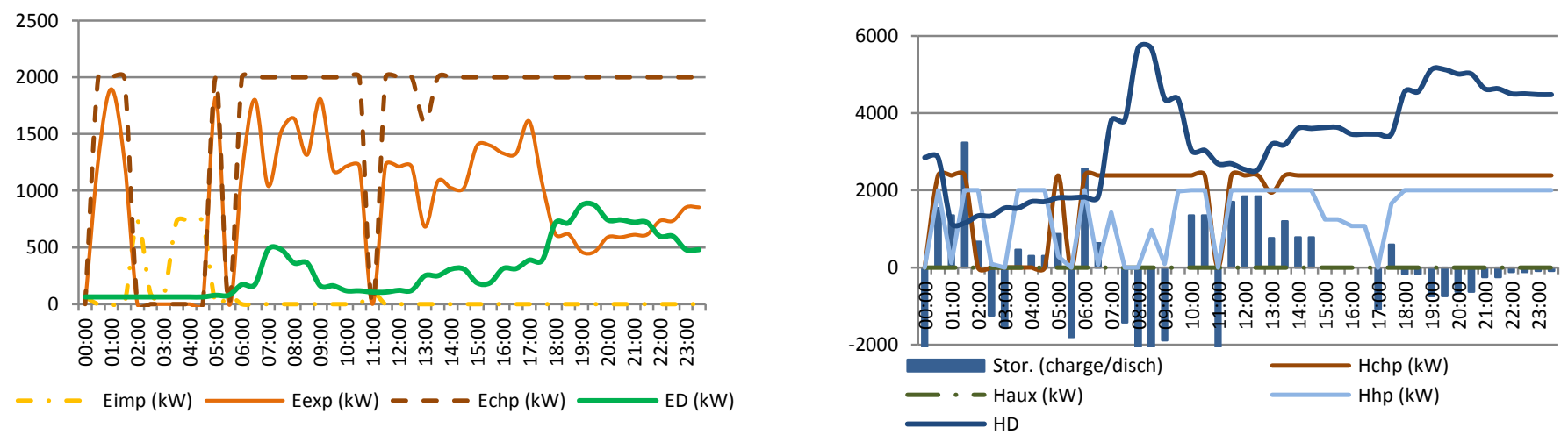

Fig. 7. Daily operation of DMG type 7 for a typical winter day - electricity and heat

\section{2) Spring/Autumn}

Spring and autumn periods are characterized by lower ratio of heat and electricity demand. This is shown in Figure 8. Some behaviour patterns in terms of consumption can be still readily recognized (morning and evening peak demands, in particular).

DMG types 4 and 5 show a very similar behaviour as for the winter day. DMG type 4 still operates with negligible flexibility, similar as a boiler covering heat demand. Adding TES improves the flexibility as the operation of the DMG type 5 is not constrained only by heat demand. Thermal storage enables storing excess heat in times of high electricity prices and also lowering CHP production during periods of low electricity prices. As the contribution of this work is primarily in showing flexibility benefits from coupling units, the focus will be on DMG types 6 and 7. Hence, the behaviour of DMG type 6 for the specific spring/autumn day is shown in Figure 9.

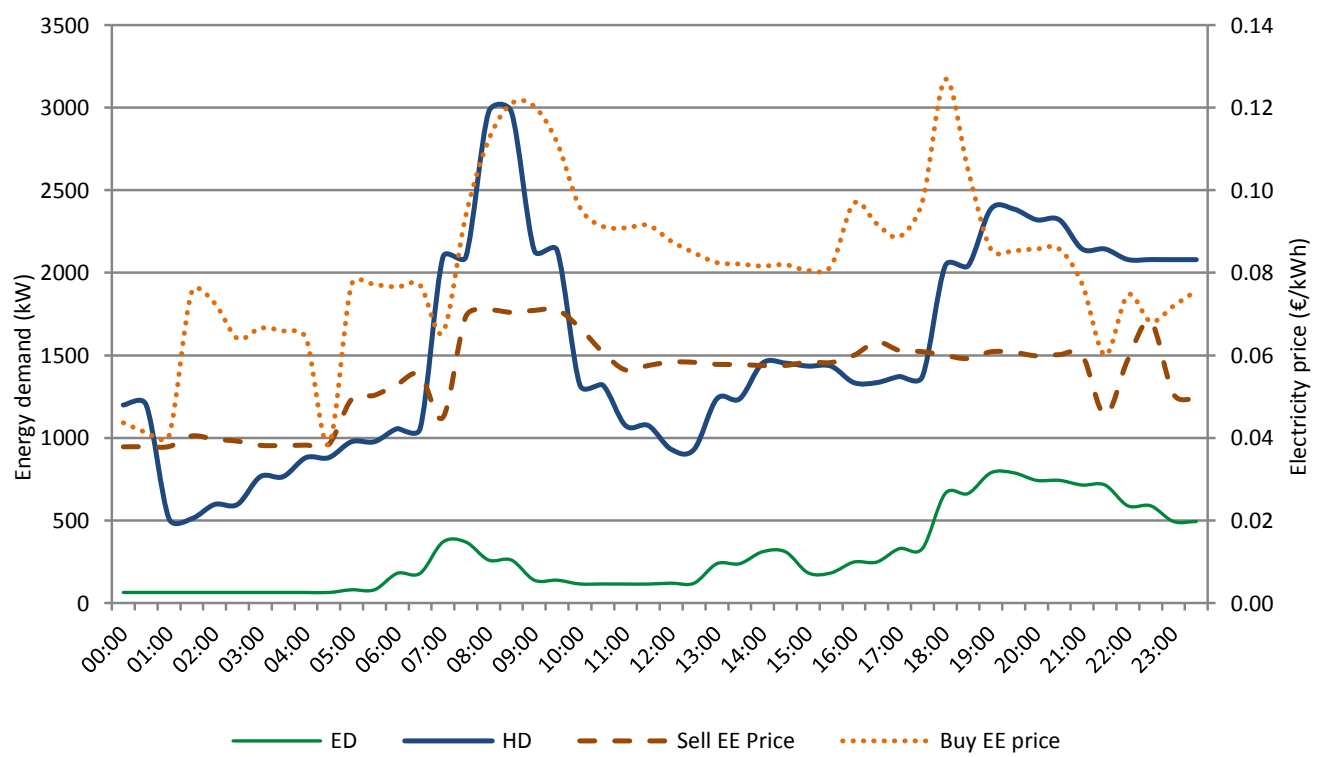

Fig. 8. Demand profiles and electricity prices for a specific spring/autumn day 

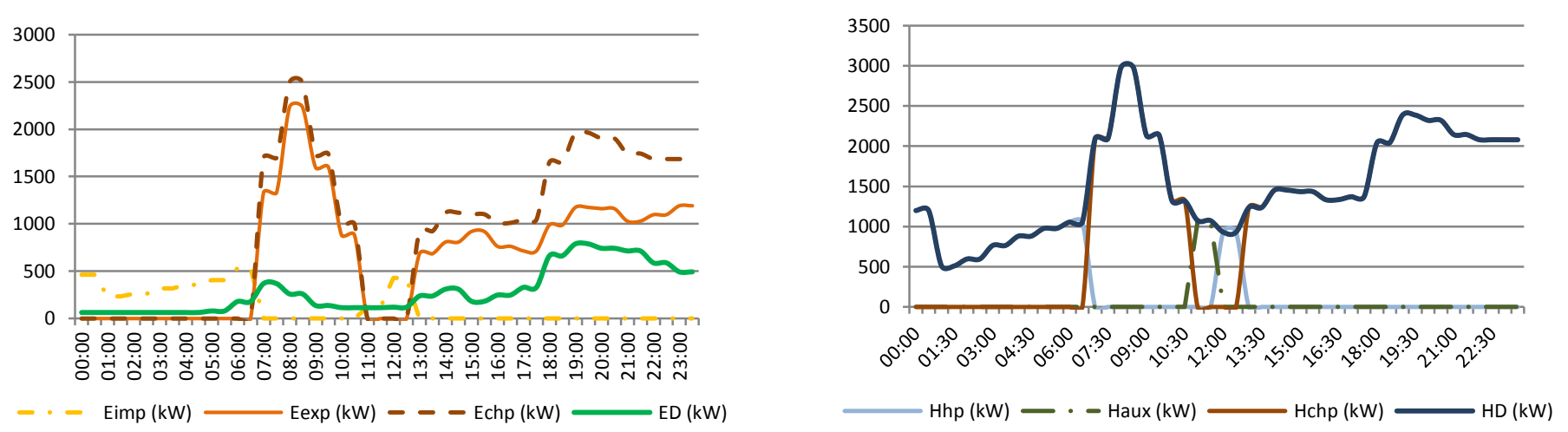

Fig. 9. Daily operation of DMG type 6 for a typical sprig/autumn day - electricity and heat

For the considered day the heat demand is, for the most part, covered by the CHP unit with the exception of morning hours. Operational behaviour for DMG type 7 is shown in Fig. 10. At the beginning of the simulation period, hours 0:30-2:00, the difference between sell and buy price is negligible and it is feasible to cover the heat demand from the EHP. Same behaviour can also be observed during hours 4:00-5:00. Between those two periods the electricity price difference is high while the heat demand is quite low; this favours storage discharging as it is not feasible to start the operation of the CHP and producing heat from the EHP is too expensive. During the period 1:00-4:00, the CHP would be operating only in heat following mode selling produced electricity into the grid at, very likely, unfavourable prices. In periods of peak demand (8:00-10:00), the heat demand is covered by the CHP. In case there is excess demand of heat, this is covered by discharging the thermal storage (period 8:009:00). Hence, the advantage of adopting DMG type 7 can be seen with respect to not only the spark spread arbitrage of gas and electricity prices as with type 6 , but also through the capability to respond to the difference between sell and buy electricity prices by exploiting storage charge/discharge as this difference increases.
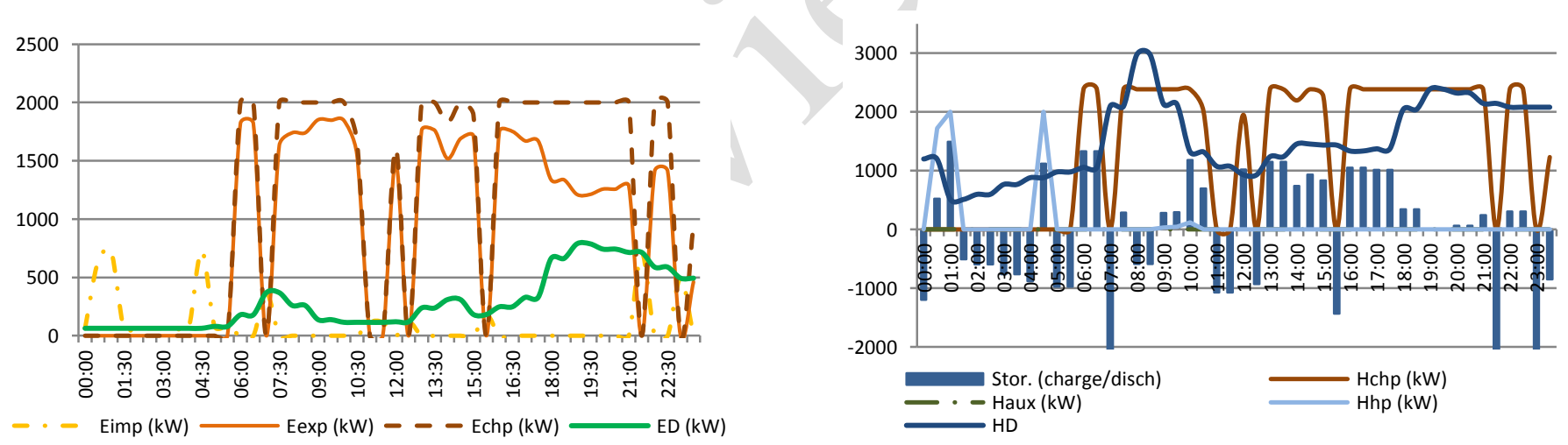

Fig. 10. Daily operation of DMG type 7 for a typical sprig/autumn day - electricity and heat

\section{3) Summer}

During summer the ratio between peak electricity and heat consumption is reduced to around 1:1.4. Figure 11 shows electricity prices and electricity and heat demand for the considered summer day. 

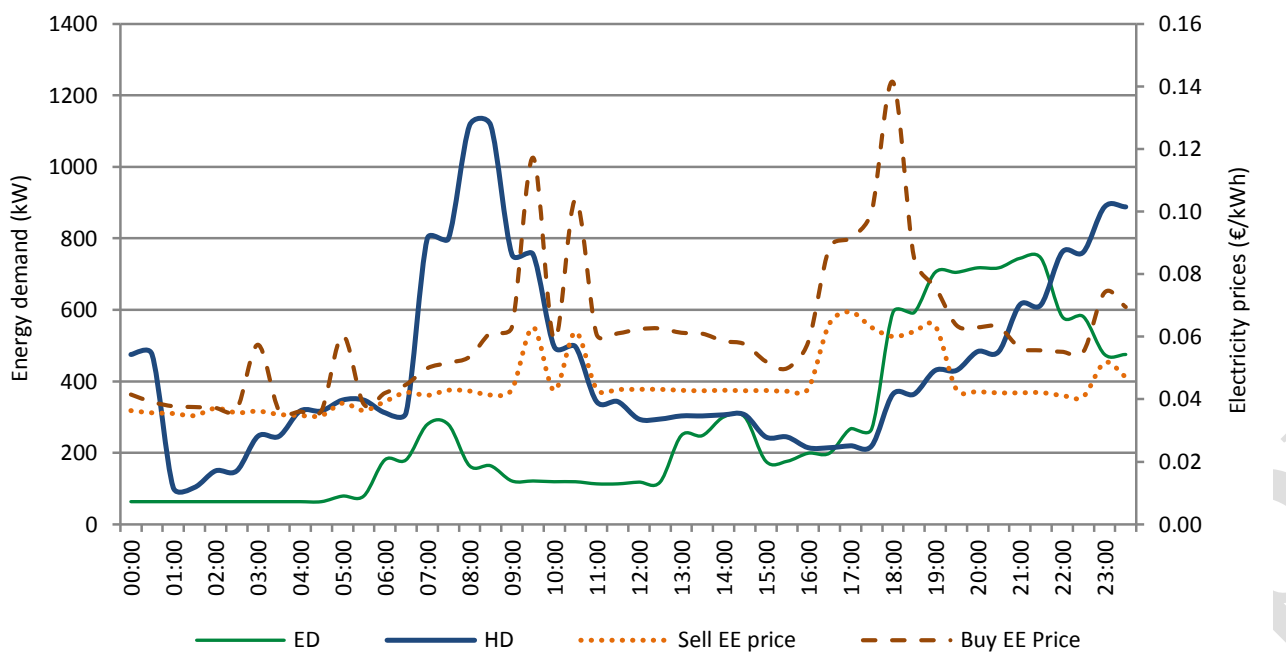

Fig. 11 Demand profiles and electricity prices for a specific summer day

The results for DMG type 4 and type 5 are again not shown and can, for the most part, be understood from simulations shown for a typical winter day. More specifically, for the summer day operation of DMG type 4 the entire heat demand is covered by the $\mathrm{AB}$ since the trade-off between producing in CHP and selling excess electricity to the grid is less favourable than running the boiler and purchasing electricity from the market.

Figures 12 shows the operation of the CHP coupled with EHP (DMG unit 6). Unlike in the spring and winter cases, during summer most of the heat demand is supplied from EHP which is driven by electricity from the grid. This can be explained with the MSG constraint of the CHP. For the larger period of the day, starting the CHP would mean excess heat production which cannot be stored.
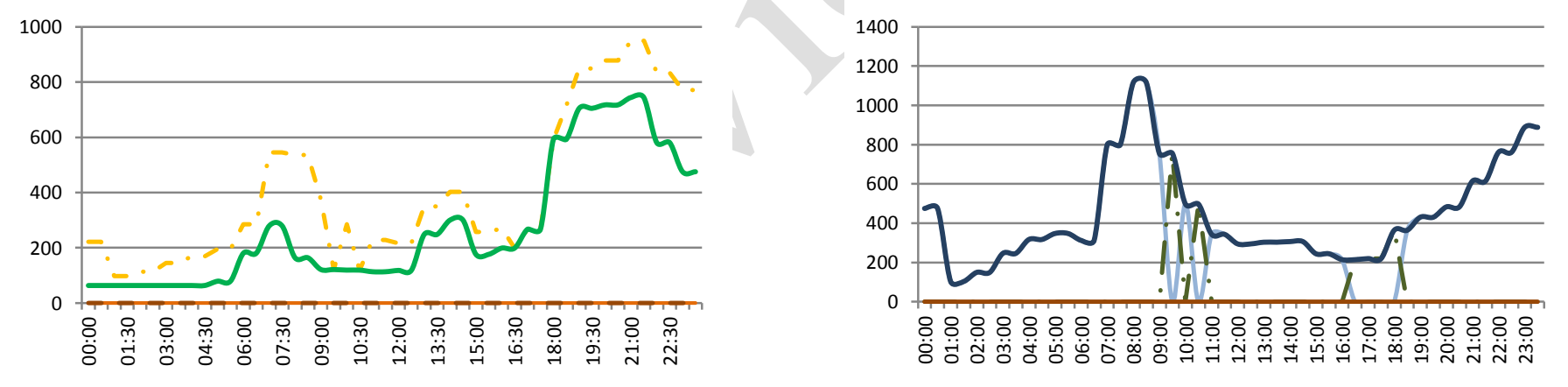

- . Eimp (kW) - Eexp (kW) - - Echp (kW) ED (kW)

$\longrightarrow \mathrm{Hhp}(\mathrm{kW})$ - - Haux (kW) $\mathrm{Hchp}(\mathrm{kW}) \longrightarrow \mathrm{HD}(\mathrm{kW})$

Fig. 12. Daily operation of DMG type 6 for a typical summer day - electricity and heat

Adding TES to the system, in DMG type 7, thus enables more flexible CHP operation, especially during peak electricity prices. This is shown in Fig. 13 (periods 9:00-11:00 and 16:00-19:00).
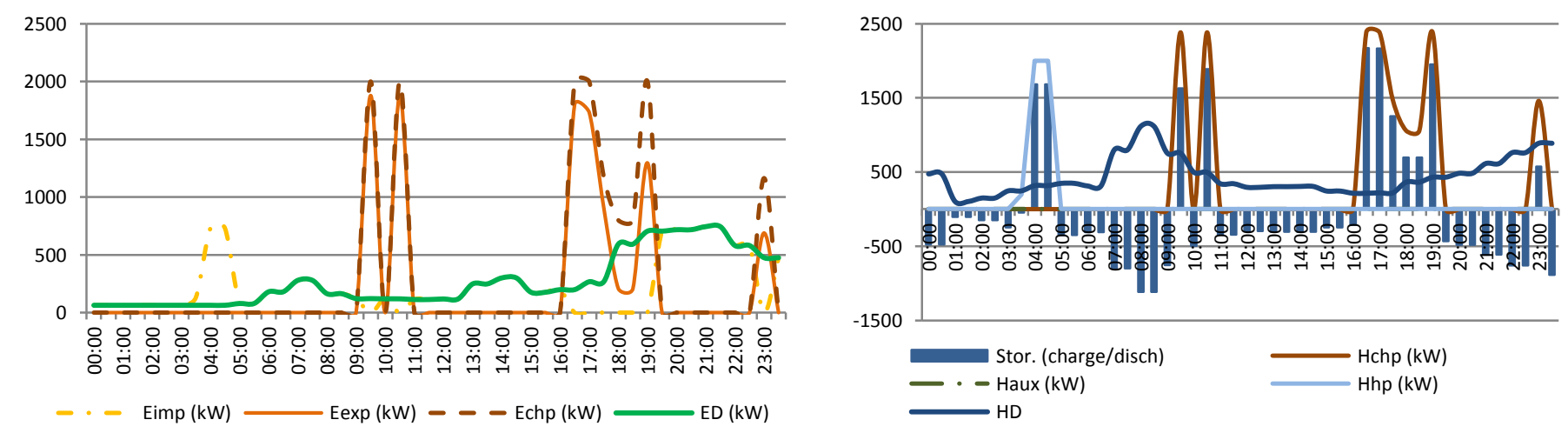

Fig. 13. Daily operation of DMG type 7 for a typical summer day - electricity and heat 


\section{Annual operational synthesis}

Analyzing daily operation profiles provides insight into understanding market behaviour of each DMG type and, for the presented studies, interactions between different units and the arising flexibility. Market conditions and load demand correlations change throughout the year so the real value of flexible systems needs to be obtained by performing annual DMG type operation analysis. This optimal operation simulates the behaviour of each DMG type for different demand profiles, different market prices, and therefore different operational aspects of each unit type. Hence, the same simulations as for daily operation are conducted taking the day-ahead UK electricity market prices for the whole 2011. The flexibility of different DMG types, demonstrated in the previous section, is supported by annual operational cost savings achieved by unit coupling. Table II provides an incremental market analysis of the benefits of the different DMG-based district heating options.

TABLE II

ANNUAL OPERATIONAL COSTS OF DIFFERENT DMG TYPES

\begin{tabular}{c|c|c}
\multirow{2}{*}{ UNIT TYPE } & OPERATIONAL COST $(\boldsymbol{\epsilon} / \mathbf{a})$ & $\boldsymbol{\Delta}$ TO REFERENCE CASE $(\boldsymbol{\%})$ \\
\hline TYPE 1 & 625,440 & - \\
\hline TYPE 2 & 479,599 & -23.3 \\
\hline TYPE 3 & 445,660 & -28.7 \\
\hline TYPE 4 & 465,130 & -25.6 \\
\hline TYPE 5 & 396,155 & -36.6 \\
\hline TYPE 6 & 339,052 & -45.8 \\
\hline TYPE 7 & 304,217 & -51.4
\end{tabular}

As said earlier, boilers have no flexibility and there is no room for operational optimization. The heat is produced when needed and electricity purchased to cover electricity demand. The annual operational cost of this unit is taken as a reference value when determining flexibility and operational savings that can be achieved from alternative options.

As also mentioned above, large and decentralized electric heat pumps are becoming a more interesting option as they have a significant potential to manage variability in renewable energy sources, especially wind, production [64]. Coupling EHP with thermal storage unit creates flexibility in terms of delaying or pushing operation of EHP not strictly related to heat consumption. Comparing these two options (types 2 and 3) to the reference case annual operation savings of $23.3 \%$ and $28.7 \%$ can be achieved.

While CHP systems may be very efficient, the flexibility of schemes based on gas turbines or combustion engines are limited, given the sole role of covering either heat or electricity demand. Adding storage to such units provides them with flexibility to respond to favourable electricity market prices. The results presented confirm this option has significant advantage compared to the base boiler case, as it achieves $36.6 \%$ annual operation cost reduction. The possibility of optimizing both sale and purchase of electricity also bring benefits compared to the EHP only options.

Techno-economic evaluation of a CHP-EHP cascade has gained little attention in the past, despite of the potential energy advantages this approach could bring. In fact, the annual operation analysis of such a concept support the conclusions based on daily simulations as cost savings compared to the reference case are $45.8 \%$ (no storage) and $51,4 \%$ (with storage). If DMG options 6 and 7 are compared to CHP-AB or CHP-AB-TES units the savings are somewhat lower although substantial, namely, $27.1 \%$ and $34.6 \%$ respectively compared to $\mathrm{CHP}-\mathrm{AB}$ and $14.4 \%$ and $23.2 \%$ respectively when compared to CHP-AB-TES. The additional benefits from CHP-EHP coupling are thus very significant in general. In addition, each unit option has been assessed according to a day-ahead market analysis only. However, high flexibility, as the one shown for DMG types 6 and 7, suggests these plants could increase their revenue even further by entering multiple markets, e.g. intraday balancing markets and ancillary services (reserve) markets, which is object of ongoing research.

\section{Sensitivity analysis on base case design parameters}

As already mentioned in Section II, sizing of the units is a result of sensitivity analyses conducted for different unit sizes and DMG market driven operation though the whole year. As DMG types 1-4 are more or less heat demand led, unit sizing in those types is essentially dictated by peak heat demand and there is little flexibility for optimal sizing. DMG unit types where EHP and/or TES are coupled to CHP have instead been analyzed in detail. The investment cost for units are taken from [16], [19]. Investment lifetime of 15 years and discount rate of 5\% were initially considered. The costs and factors taken for the investment analyses are shown in Table III. 
TABLE III

INPUT DATA FOR THE INVESTMENT ANALYSES

\begin{tabular}{|l|c|}
\hline CHP $\left(\boldsymbol{\epsilon} / \mathbf{k} \mathbf{W}_{\mathbf{e}}\right)$ & 600 \\
\hline EHP $\left(\boldsymbol{\epsilon} / \mathbf{k} \mathbf{W}_{\mathbf{t}}\right)$ & 240 \\
\hline TES $\left(\boldsymbol{\epsilon} / \mathbf{m}^{\mathbf{3}}\right)$ & 840 \\
\hline Discount rate $(\boldsymbol{\%})$ & 5 \\
\hline Investment period (years) & 15 \\
\hline
\end{tabular}

The results of investment analyses are presented in Figures 14 to 16.
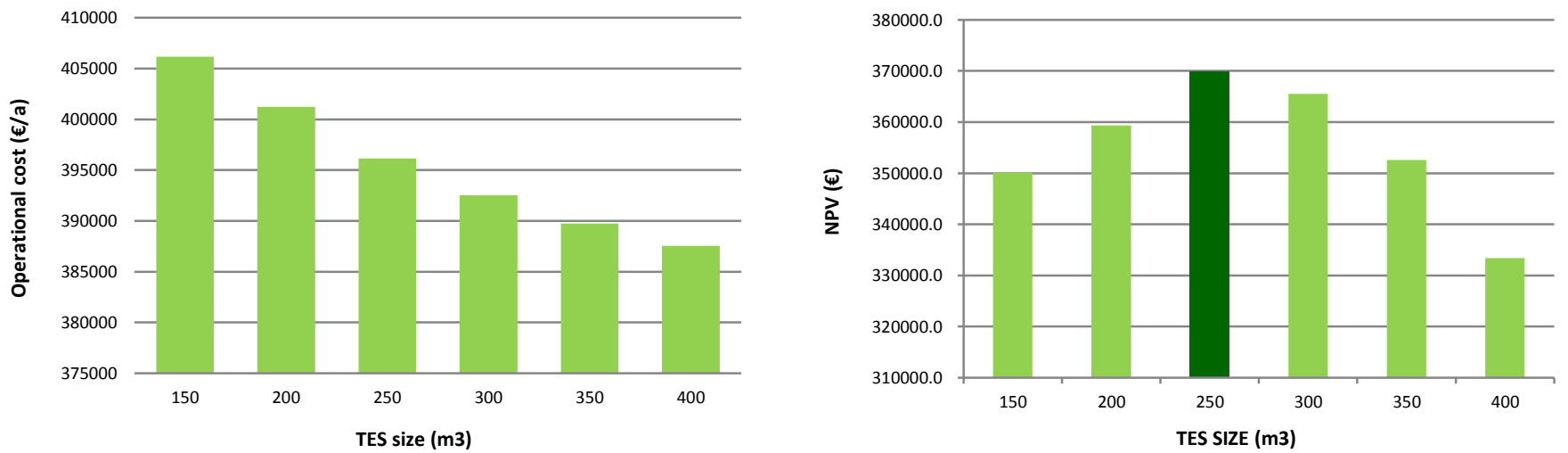

Fig. 14. Results for sensitivity analyses for DMG type 5
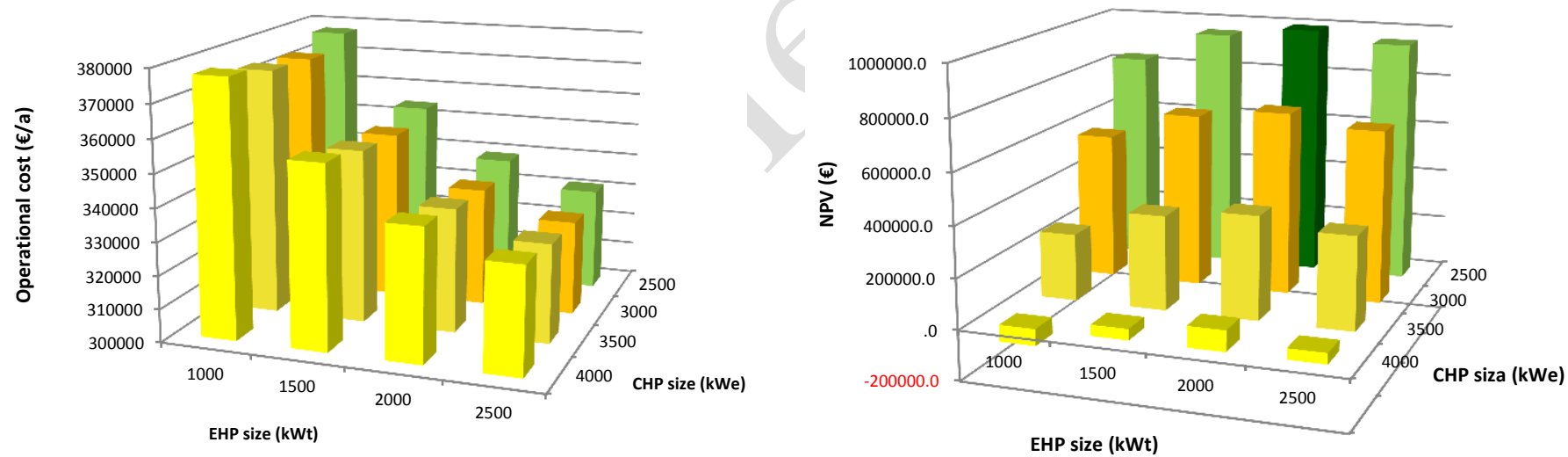

Fig. 15. Results for sensitivity analyses for DMG type 6
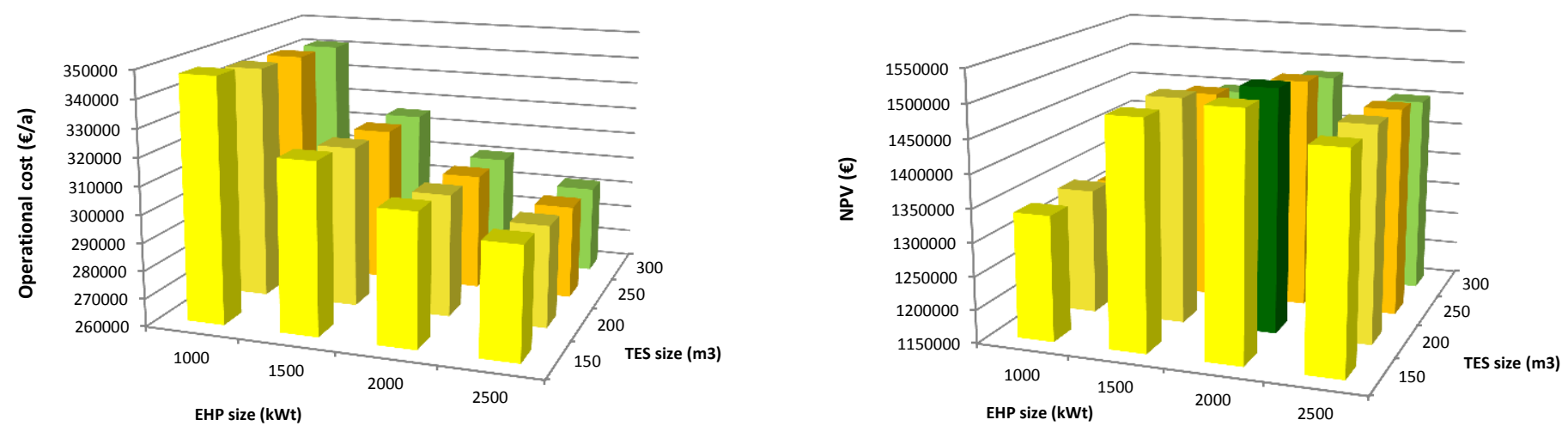

Fig. 16. Results for sensitivity analyses for DMG type 7 


\section{E. Discussion of the results, planning analysis and robustness test}

Investment analyses support the results shown for daily and annual unit operation. For DMG type 5, the flexibility of the unit is dictated by the size of TES coupled to CHP. On the other hand, larger TES means higher investment cost, which is not paid back by benefits compared to the base case of boiler-produced heat. Therefore optimal size of the TES is a trade-off between benefits and investment cost.

For DMG types 6 and 7, the electrical size ratio of CHP and EHP, in terms of heat size of the EHP given the efficiency assumptions, has higher impact on operational cost than the size of TES. The net present value (NPV) analyses confirm the operational cost result; the thermal ratio of CHP to EHP size close to 1 is the optimal unit selection.

The NPV studies are based on cash flow analyses assuming steady state prices over the plant lifetime. This assumption is neglecting investment factors such as price changes and regulatory factors, but the results are nevertheless an extremely valuable indicator of benefits that can be gained through different investment decisions. In addition, in order to further strengthen the investment analysis results, a robustness test was performed. There are multiple techniques to cope with long term uncertainties that effect investment decisions, such as multi stage uncertainty analysis [65], [66], which are outside the scope of this paper, the discount rate value was initially modified in order to show how investments depend on initial assumptions [67]. In Figure 17 sensitivity analysis with respect to different discount rate, namely, 3\%, 5\%,7\% and 10\%, is thus shown.

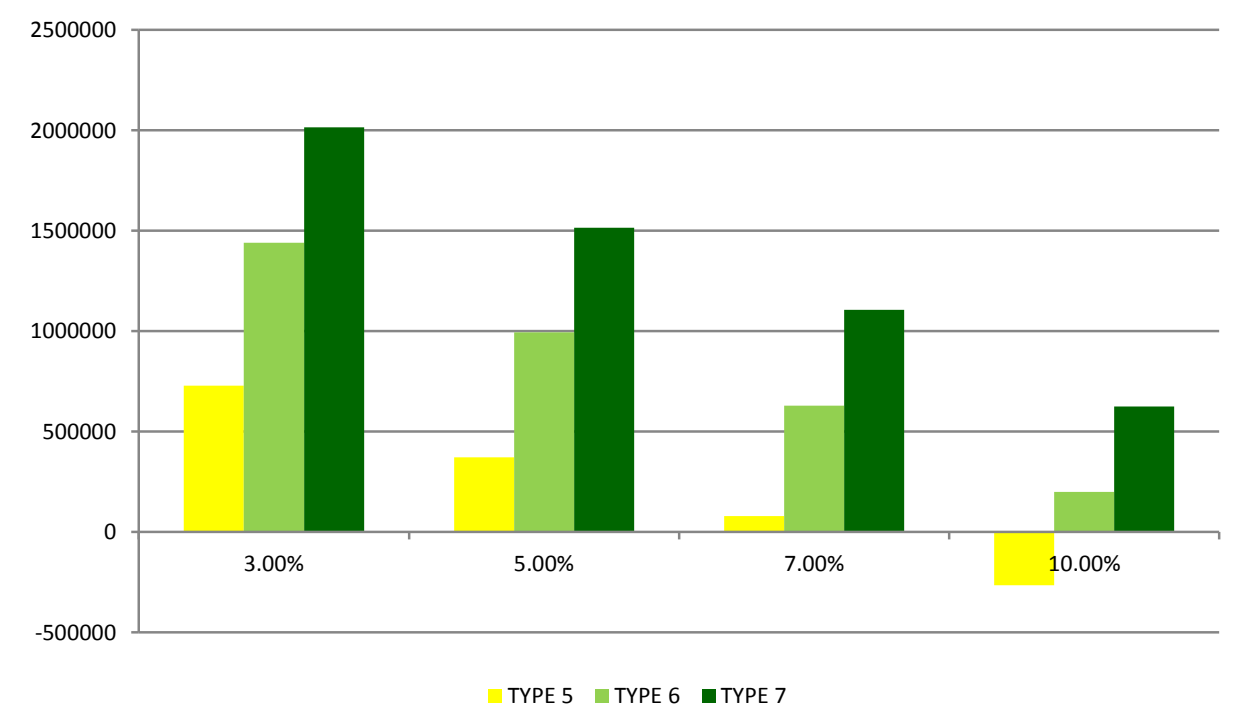

Fig. 17. NPV dependency on discount rate for different DMG types

It can be easily noticed that DMG types 6 and 7 have a positive NPV value even with higher discount rate values (when benefits gained from operational savings are somehow weighted less relative to higher initial costs), confirming that the intrinsic flexibility to respond to price signals also brings longer term benefits in terms of investment planning even for demanding investment return requirements.

As a further proof of planning option robustness, sensitivity analyses with variation of gas and electricity prices have been conducted. Input for these analyses were the optimal unit sizes calculated in the previous section and this was taken as the base scenario (Scenario 1). Gas and electricity prices were then varied $\pm 50 \%$ over 8 scenarios. The scenarios presented in Figure 18 are as follows:

1) Scenario 1: Gas and electricity prices are the same as today and these results have already been presented in Table II;

2) Scenario 2: Gas prices are increased by $50 \%$ compared to Scenario 1; electricity prices are the same as in Scenario 1;

3) Scenario 3: Electricity prices are increased by $50 \%$ compared to Scenario 1; gas prices are the same as in Scenario 1;

4) Scenario 4: Both electricity and gas prices are increased by $50 \%$ compared to Scenario 1 ;

5) Scenario 5: Gas prices are decreased by 50\% compared to Scenario 1; electricity prices are the same as in Scenario 1;

6) Scenario 6: Electricity prices are decreased by $50 \%$ compared to Scenario 1; gas prices are the same as in Scenario 1;

7) Scenario 7: Both electricity and gas prices are decreased by $50 \%$ compared to Scenario 1 ;

8) Scenario 8: Electricity prices are increased by $50 \%$ compared to Scenario 1; gas prices are decreased by $50 \%$ compared to Scenario 1; 
9) Scenario 9: Gas prices are increased by 50\% compared to Scenario 1; electricity prices are decreased by 50\% compared to Scenario 1;

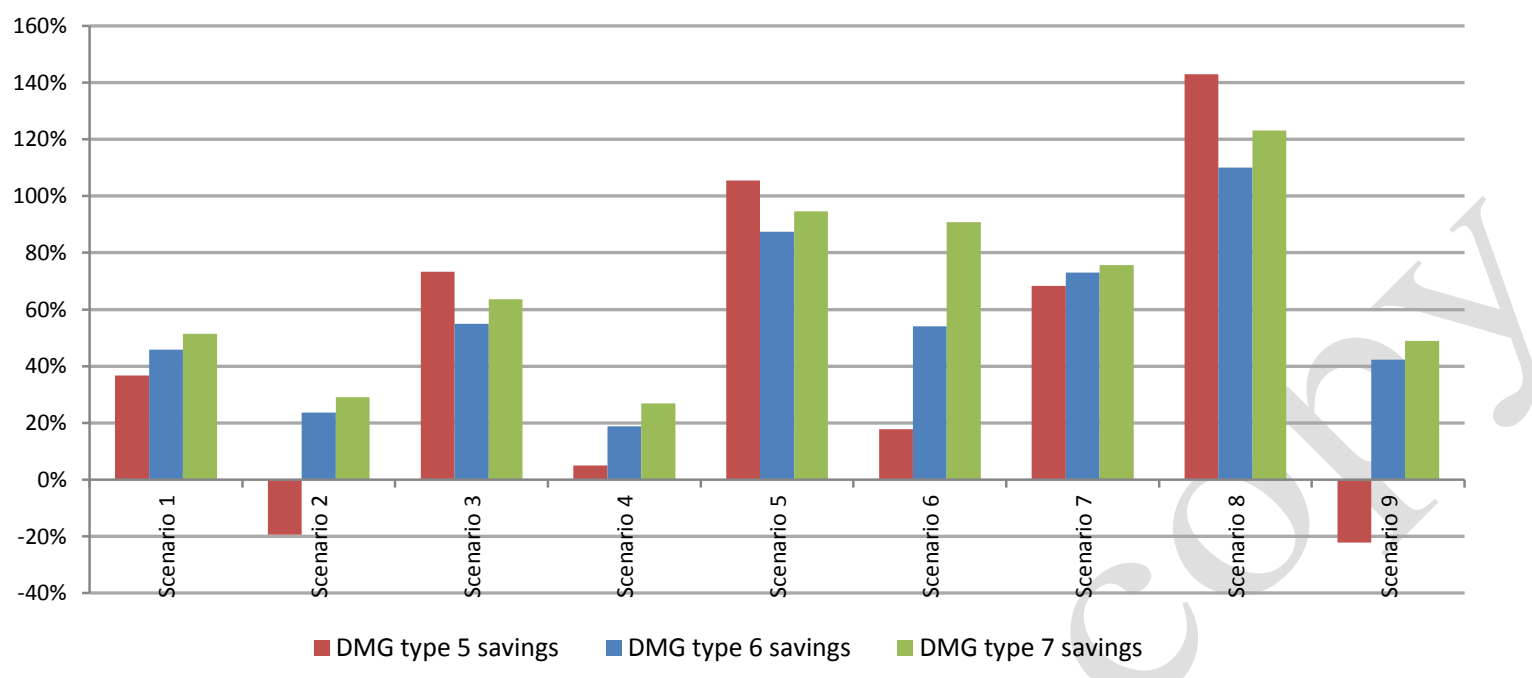

Fig. 18. Sensitivity analyses for DMG types 5, 6 and 7

The results presented in Figure 18 show the dependency of the compared results on the unit sizing that was performed for base case (in Section III D). This particularly refers to the size of the CHP as this is relevant to the electricity that can be produced by the CHP and sold back to the market. DMG type 5 CHP coupled with TES shows stronger dependence on gas and electricity price ratio than other two types. Larger optimal size of the CHP unit results in the operation that is highly oriented towards selling excess electricity in order to reduce operational cost. For this reason scenarios where price difference of electricity to gas increases in favour of electricity (Scenario 5 and Scenario 8) results in higher operational savings for DMG type 5.

For different gas and electricity prices market driven analyses of DMG types 6 and 7 the results shown in Figure 18 support the conclusions from the previous Section. In fact, they even suggest that current gas and electricity price spark spread is one of the least favourable in supporting the economic benefits from these flexible units. In scenario 8, where gas prices are increased by $50 \%$ and electricity prices are reduced by $50 \%$, district systems based on boiler are even economically favourable to this DMG option. This sensitivity to prices of DMG type 5 as well as different CHP size compared to DMG type 7 is also shown when comparing these two types.

\section{F. Primary energy saving assessment}

For each of the DMG options that have been analysed, the PPES indicator has been used to assess the relevant primary energy saving with respect to type one (heat produced in a district heating boiler and electricity produced in centralized generation) which is considered the SP reference (and is assigned a PPES value 0.0).

Primary energy saving is by definition independent of the fuel (see for instance references [51], [52], where a comprehensive analysis of the differences between primary energy and emissions and of their relation with fuels is given). However, the reference efficiencies could be selected according to different arguments, for instance by considering only those power plants with the same type of fuel as the considered DMG system as opposed to the whole power system. Both types of studies were therefore run. More specifically, in order to compare the different DMG options considered here with the overall power system, the average power system efficiency of the UK in 2012 was considered, estimated to be around 0.38 [68], also taking into account transmission and distribution losses in the order of $7 \%$. Reference boiler efficiency equal to 0.85 was also assumed. In addition, the PPES indicator was also calculated with respect to state of the art gas CCGT with 55\% efficiency and gas boilers with 95\% efficiencies. The relevant results are shown in Table IV. The results clearly show that the highest primary energy savings are achieved in DMG type 7, where a PPES in the order of $41.7 \%$ can be achieved with respect to the average power systems production. In addition, while the PPES is lower when considering only gas CCGT units in the comparison, still DMG options provide substantial energy saving of up to $31.7 \%$ for DMG type 7. It is also very interesting to highlight how, from the comparison between CHP-EHP mixed schemes (type 6 and 7) and CHP only (types 4 and 5), the higher flexibility DH schemes 6 and 7 bring substantial benefits with respect to "conventional" simultaneous production of energy vectors in CHP. 
Furthermore, moving from type 4 to type 7, the additional energy savings are much more substantial when CCGT plants are used as the reference case (with benefits that pass from 6.5\% to 31.7\%) than when the average power system is considered. This is because the combination of CHP and EHP allows an optimal use of local resources and at higher efficiency than with CHP or EHP only. This also implies that less electricity is exchanged externally, which is particularly beneficial when the reference system becomes more efficient as in the case of CCGT plants.

TABLE IV

MODELLING DIFFERENCES IN PRIMARY ENERGY SAVINGS FOR DIFFERENT DMG OPTIONS

\begin{tabular}{|l|c|c|c|c|c|c|c|}
\hline & DMG TYPE 1 & DMG TYPE 2 & DMG TYPE 3 & DMG TYPE 4 & DMG TYPE 5 & DMG TYPE 6 & DMG TYPE 7 \\
\hline PPES (UK avg. 2012) & 0.000 & 0.181 & 0.183 & 0.268 & 0.286 & 0.394 & 0.417 \\
\hline PPES (CCGT) & 0.000 & 0.309 & 0.318 & 0.065 & 0.079 & 0.289 & 0.317 \\
\hline
\end{tabular}

\section{G. $\mathrm{CO}_{2}$ emission reduction}

Regarding the $\mathrm{CO}_{2}$ emission reduction assessment of the different DMG options, a gas emission factor value of $0.19 \mathrm{~kg}$ $\mathrm{CO}_{2} / \mathrm{kWh}$ was used for the CHP units and the boiler, as shown in [69]. Emission rate for electricity values are reconstructed as in [70] using the electricity generation mix for the entire 2011 and 2012 [58] and the standard emission rates for each fuel type [71]. A transmission and distribution loss factor of 1.1 (that is, $10 \%$ losses) was taken into account too. The resulting grid halfhourly $A E F$ for the years 2011 and 2012 are shown in Figure 19.

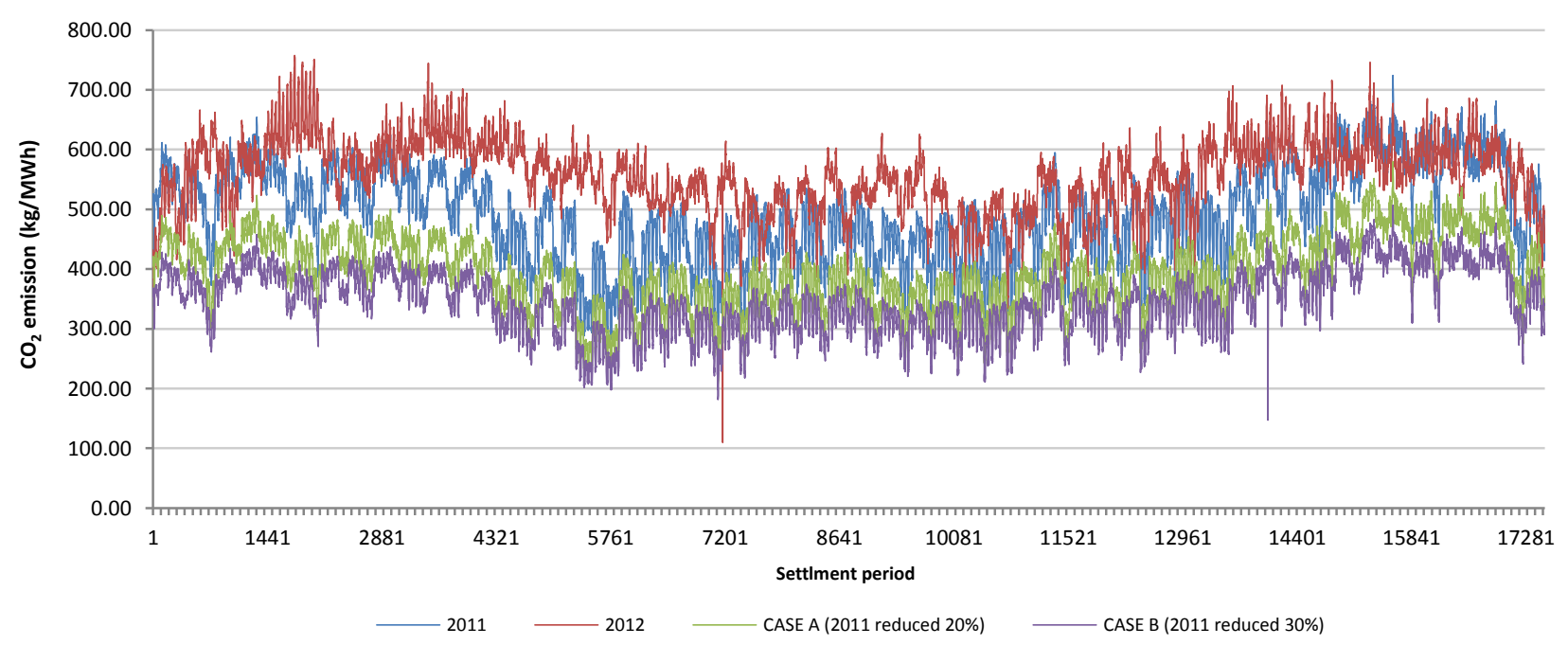

Fig. 19. Half hourly Average Emission Factor for UK in 2011 and 2012

For a comprehensive environmental analysis of the different options, several case studies were defined:

1) Case 2011: $A E F$ as in 2011 for each half hour period as shown in Figure 18, gas emission factor of $0.19 \mathrm{~kg} \mathrm{CO}_{2} / \mathrm{kWh}$;

2) Case 2012: $A E F$ as in 2012 for each half hour period as shown in Figure 18, gas emission factor of $0.19 \mathrm{~kg} \mathrm{CO}_{2} / \mathrm{kWh}$;

3) Case A: AEF reduced by $20 \%$ compared to the one in 2011 , gas emission factor of $0.19 \mathrm{~kg} \mathrm{CO}_{2} / \mathrm{kWh}$;

4) Case B: $A E F$ reduced by $30 \%$ compared to the one in 2011 , gas emission factor of $0.19 \mathrm{~kg} \mathrm{CO}_{2} / \mathrm{kWh}$;

5) Case A1: $A E F$ reduced by $20 \%$ compared to the one in 2011, gas emission factor of $0.17 \mathrm{~kg} \mathrm{CO}_{2} / \mathrm{kWh}$;

6) Case B1: $A E F$ reduced by $30 \%$ compared to the one in 2011, gas emission factor of $0.17 \mathrm{~kg} \mathrm{CO}_{2} / \mathrm{kWh}$.

Case $A$ and Case B, corresponding to reduced grid intensity scenarios, represent potential emission reduction that can be achieved at the system level by for instance integrating Carbon Capture Storage to coal/gas fired power plants and by increasing penetration of wind. An approximation has been made assuming that system dynamics and flexibility as well as emission profile would not change dramatically. More correct values could be gained by simulating future power generation mix and its operation according to forecasted fuel and electricity prices, but this is out of the scope of this paper. The approximations made 
should be viewed in the light of bringing a high level view on the DMG environmental impact in future less carbon intensive power systems and as such the studies are valuable in terms of strategic understanding.

Case Al and Case BI are based on the ongoing research, conducted mostly by the gas companies, on mixing biogas or bio methane (or other types of low-carbon gas such as hydrogen produced through renewables) with natural gas [72], [73]. In this respect National Grid published a research report on energy and economic potential of renewable gas [74], while the Department of Energy and Climate Change issued a guide for producers to connect to the existing gas grid [75]. Bio-methane producers in UK are even, under Renewable Heat Incentive, eligible for an incentive for each kWh of bio methane injected into the gas grid [76]. The presented cases assume for illustrative and exemplificative purposes that injecting low-carbon gas into the gas grid will reduce the overall gas emission factor by $10 \%$.

The results of the six scenario studies are presented in Figure 20.

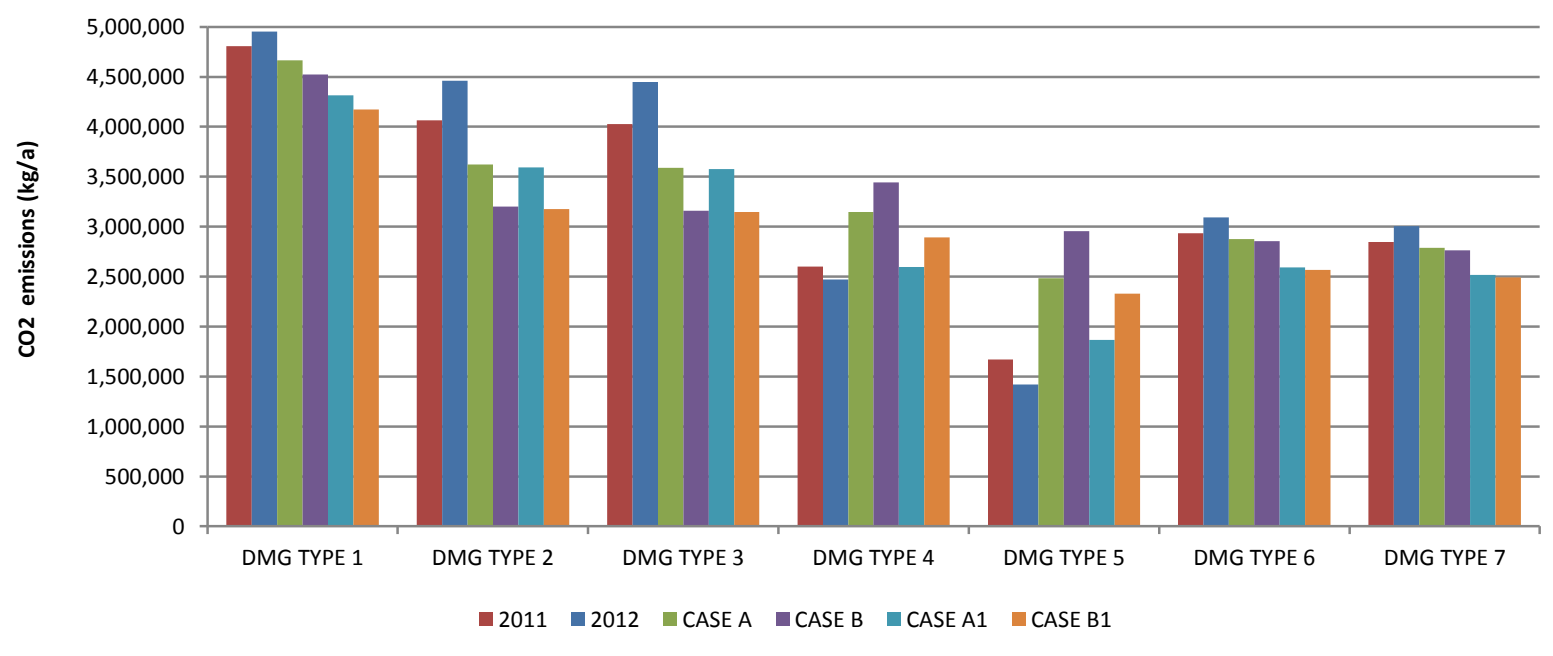

Fig. 20. DMG options carbon footprint

The results presented in Figure 20 confirm the previous findings: $\mathrm{CO}_{2}$ emissions of specific DMG unit are highly dependent on the system level emissions. As the UK electricity production is based on fossil fuels, and thus has high average $\mathrm{CO}_{2}$ system emission rate, DMG types 2 and 3 based on EHP result in highest annual emissions. Still, these two options are environmentally more favourable than boiler based DH options. Emissions are further reduced for DMG types based on CHP; in some cases over 50\% reduction can be achieved. Scenario emissions for 2011 and 2012 suggest that DMG types 4 and 5 are environmentally friendlier than more flexible DMG units type 6 and 7. As the latter two (type 6 and 7) are smaller in size, by 33\%, they produce less electricity and therefore displace less electricity that would need to be produced in highly polluting central power plants, in line with the above discussions on the primary energy saving. This can be easily seen by comparing scenarios for 2011 and 2012; DMG types 4 and 5 are the only ones with lower $\mathrm{CO}_{2}$ emissions in the more carbon intensive 2012. Analyses for cases with lower system $\mathrm{CO}_{2}$ emissions (Cases A, B, A1, B1) suggest that even just $10 \%$ decrease in gas carbon intensity could retain substantial environmental benefits for gas based DMG technologies. These results are relevant to ongoing discussion on the role that gas could play in the next years, as mentioned above. All these options could be readily evaluated under the presented unified modelling framework.

In addition, although not captured in the studies performed here, flexible DMG options can also bring benefits in terms of capability to balance intermittent renewable resources in close to real time and then integrate additional renewable at a system level. These further benefits are being analysed systematically by the authors in ongoing research.

\section{H. Local emission reduction}

For the local emission assessment, $\mathrm{NO}_{\mathrm{x}}$ and $\mathrm{CO}$ emissions have been considered here as they are the biggest concern from a regulatory point of view. The results for the different DMG options are reported in Table V. For this purpose, the following emission factors have been used: $\mu_{N O x}^{W}=700 \mathrm{mg} / \mathrm{kWh}_{\mathrm{e}}$ and $\mu_{C O}^{W}=400 \mathrm{mg} / \mathrm{kWh}_{\mathrm{e}}$ for CHP units [49] and $\mu_{N O x}^{H, S P}=200 \mathrm{mg} / \mathrm{kWh}$ and $\mu_{C O}^{H, S P}=40 \mathrm{mg} / \mathrm{kWh}_{\mathrm{t} .}$ for boilers [54]. 
Energy, Accepted for publication, 2014

TABLE V

LOCAL EMISSIONS ASSESSMENTS FOR DIFFERENT DMG OPTIONS

\begin{tabular}{|l|c|c|c|c|c|c|c|}
\hline & DMG type 1 & DMG type 2 & DMG type 3 & DMG type 4 & DMG type 5 & DMG type 6 & DMG type 7 \\
\hline NO $_{\mathbf{x}}(\mathbf{t} / \mathbf{a})$ & 3.151 & 0.196 & 0.117 & 6.933 & 7.555 & 3.394 & 3.218 \\
\hline $\mathbf{C O}(\mathbf{t} / \mathbf{a})$ & 0.630 & 0.039 & 0.023 & 3.607 & 4.097 & 1.887 & 1.891 \\
\hline
\end{tabular}

District heating units based on EHP emit the smallest amount of local emissions as they only use fossil fuels to run auxiliary boiler for backup when the price spark spread between bought electricity and gas is in favour of gas. These results were expected and the idea of this analysis was to evaluate the best option from the CHP based ones (DMG types 4, 5, 6 and 7) and to compare them with base case of boiler DH units. The results support the results from the studies performed above; besides being the best option economically, DMG type 7 has the lowest environmental impact. When comparing this option to the reference one, where electricity is produced in conventional power plants and local emissions are thus displaced, DMG type 7 and boiler based $\mathrm{DH}$ options have the same emissions in terms of $\mathrm{NO}_{\mathrm{x}}$. As the impact of these pollutants is relatively limited to in the order of tens of kilometres, these analyses are valuable when deciding on future investments, especially in high populated areas where recipients are close to the pollutant emitters.

\section{CONCLUSION}

This paper has introduced a comprehensive techno-economic and environmental analysis framework, supported by a relevant unified and synthetic mathematical operational optimization model based on MILP, to compare high efficiency and high flexibility DMG options for district energy system applications. Focusing on the enhanced operational flexibility allowed by integration of multi-energy systems to respond to price signals, economic benefits of different options have been analysed and discussed for both operational and planning purposes. A comprehensive environmental assessment through global (primary energy and $\mathrm{CO}_{2}$ emission reduction) and local ( $\mathrm{NO}_{\mathrm{x}}$ and $\mathrm{CO}$ pollutants) emission analysis has also been performed for different options. The results highlight how flexible integrated schemes with CHP and EHP, in case supported by TES, can bring significant operational and investment cost savings, primary energy saving, and emission reduction, compared to the reference case of DH boiler or less flexible options. The benefits found prove to be robust under a number of assumptions and scenarios, including cases when decarbonisation of the gas sector could go along with decarbonisation of electricity one. Further benefits from flexible utilization of integrated CHP-EHP schemes could accrue by playing in other markets such as for ancillary services, whose assessments are being carried out by the authors as part of their ongoing research [31], [32].

\section{REFERENCES}

[1] P. Mancarella, MES (multi-energy systems): an overview of concepts and evaluation models, Energy. (n.d.).

[2] C. Weber, N. Shah, Optimisation based design of a district energy system for an eco-town in the United Kingdom, Energy. 36 (2011) 1292-1308.

[3] H. Aki, T. Oyama, K. Tsuji, Analysis of energy pricing in urban energy service systems considering a multiobjective problem of environmental and economic impact, IEEE Trans. Power Syst. 18 (2003) 1275-1282.

[4] V. Curti, D. Favrat, M.R. von Spakovsky, An environomic approach for the modeling and optimization of a district heating network based on centralized and decentralized heat pumps, cogeneration and/or gas furnace. Part II: Application, Int. J. Therm. Sci. 39 (2000) 731-741.

[5] J.H. Horlock, Advanced Gas Turbine Cycles, Elsevier, 2003.

[6] A. Martens, The energetic feasibility of CHP compared to the separate production of heat and power, Appl. Therm. Eng. 18 (1998) 935-946.

[7] C. a. Frangopoulos, A method to determine the power to heat ratio, the cogenerated electricity and the primary energy savings of cogeneration systems after the European Directive, Energy. 45 (2012) 52-61.

[8] M.F. Torchio, G. Genon, A. Poggio, M. Poggio, Merging of energy and environmental analyses for district heating systems, Energy. 34 (2009) 220-227.

[9] C. Weber, D. Favrat, Conventional and advanced CO2 based district energy systems, Energy. 35 (2010) 5070-5081.

[10] P. Mancarella, C. Gan, G. Strbac, Evaluation of the impact of electric heat pumps and distributed CHP on LV networks, in: PowerTech, 2011 IEEE, IEEE, Trondheim, 2011: pp. 1-7.

[11] H. Lund, a. N. Andersen, Optimal designs of small CHP plants in a market with fluctuating electricity prices, Energy Convers. Manag. 46 (2005) 893-904.

[12] G. Westner, R. Madlener, Development of cogeneration in Germany: A mean-variance portfolio analysis of individual technology's prospects in view of the new regulatory framework, Energy. 36 (2011) 5301-5313.

[13] E. Dotzauer, Experiences in mid-term planning of district heating systems, Energy. 28 (2003) 1545-1555. 
[14] B. Rolfsman, Combined heat-and-power plants and district heating in a deregulated electricity market, Appl. Energy. 78 (2004) $37-$ 52 .

[15] J. Associates, Micro-CHP as an integral component of the UK' s energy strategy, 2011.

[16] G. Davies, The potential and Cost of District Heating Networks, 2009.

[17] H. Singh, a. Muetze, P.C. Eames, Factors influencing the uptake of heat pump technology by the UK domestic sector, Renew. Energy. 35 (2010) 873-878.

[18] A. Fragaki, A.N. Andersen, Conditions for aggregation of CHP plants in the UK electricity market and exploration of plant size, Appl. Energy. 88 (2011) 3930-3940.

[19] A. Fragaki, A.N. Andersen, D. Toke, Exploration of economical sizing of gas engine and thermal store for combined heat and power plants in the UK, Energy. 33 (2008) 1659-1670.

[20] Ecoheat4eu, (ecoheat4.eu/en/District-Heating-Barometer).

[21] M. Blarke, H. Lund, Large-scale heat pumps in sustainable energy systems: System and project perspectives, Therm. Sci. 11 (2007) $143-152$.

[22] B. Mathiesen, M. Blarke, K. Hansen, D. Connolly, The role of large-• scale heat pumps for short term integration of renewable energy, 2011.

[23] B.V.M.H. Lund, Comparative analyses of seven technologies to facilitate the integration of fluctuating renewable energy sources, IET Renew. Power Gener. 3 (2009) 190-204.

[24] P. Mancarella, G. Chicco, Distributed multi-generation systems: Energy models and analyses, Nova Science Publishers, 2009.

[25] G. Chicco, P. Mancarella, Distributed multi-generation: A comprehensive view, Renew. Sustain. Energy Rev. 13 (2009) 535-551.

[26] Z. Bogdan, D. Kopjar, Improvement of the cogeneration plant economy by using heat accumulator, Energy. 31 (2006) $2285-2292$.

[27] A. Gebremedhin, Introducing District Heating in a Norwegian town - Potential for reduced Local and Global Emissions, Appl. Energy. 95 (2012) 300-304.

[28] V. Curti, M.R. von Spakovsky, D. Favrat, An environomic approach for the modeling and optimization of a district heating network based on centralized and decentralized heat pumps, cogeneration and/or gas furnace. Part I: Methodology, Int. J. Therm. Sci. 39 (2000) 721-730.

[29] P. Mancarella, Cogeneration systems with electric heat pumps: Energy-shifting properties and equivalent plant modelling, Energy Convers. Manag. 50 (2009) 1991-1999.

[30] P.C. Few, M. a. Smith, J.W. Twidell, Modelling of a combined heat and power (CHP) plant incorporating a heat pump for domestic use, Energy. 22 (1997) 651-659.

[31] P. Mancarella, G. Chicco, Demand Response from Energy Shifting in Distributed Multi-Generation, IEEE Trans. Smart Grid. In Press (2014).

[32] P. Mancarella, G. Chicco, Integrated Energy and Ancillary Services Provision in Multi-Energy Systems, in: 2013 IREP Symp. Power Syst. Dyn. Control, 2013: pp. 1-19.

[33] M.B. Blarke, Towards an intermittency-friendly energy system: Comparing electric boilers and heat pumps in distributed cogeneration, Appl. Energy. 91 (2012) 349-365.

[34] M.B. Blarke, E. Dotzauer, Intermittency-friendly and high-efficiency cogeneration: Operational optimisation of cogeneration with compression heat pump, flue gas heat recovery, and intermediate cold storage, Energy. 36 (2011) 6867-6878.

[35] H.B. Piittgen, P.R. Macgregor, Optimum Scheduling Procedure For Cogenerating Small Power Producing Facilities,, IEEE Trans. Power Syst. 4 (1989).

[36] P.R. Macgregor, H.B. Puttgen, A Spot Price Based Control Mechanism For Electric Utility Systems With Small Power Producing Facilities, IEEE Trans. Power Syst. (1991) 683-690.

[37] P.S.N. Rao, Combined Heat and Power Economic Dispatch: A Direct Solution, Electr. Power Components Syst. 34 (2006) 10431056.

[38] M.I. Henwood, M. van Ooijen, An algorithm for combined heat and power economic dispatch, IEEE Trans. Power Syst. 11 (1996) $1778-1784$.

[39] K. Heussen, S. Koch, A. Ulbig, G. Andersson, Energy Storage in Power System Operation : The Power Nodes Modeling Framework, in: Innov. Smart Grid Technol. Conf. Eur. (ISGT Eur. 2010 IEEE PES, 2010: pp. 1-8.

[40] F. Salgado, P. Pedrero, Short-term operation planning on cogeneration systems: A survey, Electr. Power Syst. Res. 78 (2008) $835-$ 848 .

[41] O. a. Shaneb, P.C. Taylor, G. Coates, Optimal online operation of residential $\mu$ CHP systems using linear programming, Energy Build. 44 (2012) 17-25.

[42] F. Freschi, L. Giaccone, P. Lazzeroni, M. Repetto, Economic and environmental analysis of a trigeneration system for food-industry: A case study, Appl. Energy. 107 (2013) 157-172.

[43] E.D. Mehleri, H. Sarimveis, N.C. Markatos, L.G. Papageorgiou, A mathematical programming approach for optimal design of distributed energy systems at the neighbourhood level, Energy. 44 (2012) 96-104.

[44] G.M. Kopanos, M.C. Georgiadis, E.N. Pistikopoulos, Energy production planning of a network of micro combined heat and power generators, Appl. Energy. 102 (2013) 1522-1534.

[45] I.E. Grossmann, S.A. Papoulias, A Structural Optimization Approach Process Syntesis-I Utility Systems, Comput. Chem. Eng. 7 (1983).

[46] I.E. Grossmann, S.A. Papoulias, A Structural Optimization Approach Process Synthesis-II Heat Recovery Networks, Comput. Chem. Eng. 7 (1983) 707-721.

[47] P. Voll, C. Klaffke, M. Hennen, A. Bardow, Automated superstructure-based synthesis and optimization of distributed energy supply systems, Energy. 50 (2013) 374-388.

[48] P. Voll, M. Lampe, G. Wrobel, A. Bardow, Superstructure-free synthesis and optimization of distributed industrial energy supply systems, Energy. 45 (2012) 424-435.

[49] Environmental Protection Agency Combined Heat and Power Partnership, Technology Characterization: Reciprocating Engines, Washington, DC, 2008. 
[50] P.S. Woods, G. Zdaniuk, CHP and District Heating - how efficient are these technologies?, in: CIBSE Tech. Symp., 2011: pp. 1-17.

[51] G. Chicco, P. Mancarella, Trigeneration primary energy saving evaluation for energy planning and policy development, Energy Policy. 35 (2007) 6132-6144.

[52] G. Chicco, P. Mancarella, A unified model for energy and environmental performance assessment of natural gas-fueled polygeneration systems, Energy Convers. Manag. 49 (2008) 2069-2077.

[53] P. Mancarella, G. Chicco, Distributed Cogeneration : Modelling of Environmental Benefits and Impact, in: D N Gainkar (Ed.), Distrib. Gener., InTech, 2010.

[54] P. Mancarella, G. Chicco, Global and local emission impact assessment of distributed cogeneration systems with partial-load models, Appl. Energy. 86 (2009) 2096-2106.

[55] A. Canova, G. Chicco, G. Genon, P. Mancarella, Emission characterization and evaluation of natural gas-fueled cogeneration microturbines and internal combustion engines, Energy Convers. Manag. 49 (2008) 2900-2909.

[56] Demand Profile Generator, (n.d.).

[57] V. Verda, E. Guelpa, A. Kona, S. Lo Russo, Reduction of primary energy needs in urban areas trough optimal planning of district heating and heat pump installations, Energy. 48 (2012) 40-46.

[58] Elexon, (www.elexonportal.co.uk).

[59] Department of Energy\&Climate Change, (www.gov.uk/government/organisations/department-of-energy-climatechange/series/energy-price-statistics).

[60] V. Verda, F. Colella, Primary energy savings through thermal storage in district heating networks, Energy. 36 (2011) $4278-4286$.

[61] M. Blarke, Smart intermittency-friendly cogeneration: Techno-economic performance of innovative double storage concept for integrating compression heat pumps in distributed cogeneration, in: 6th Int. Renew. Energy Storage Conf., 2011: pp. 1-20.

[62] A. Pini Prato, F. Strobino, M. Broccardo, L. Parodi Giusino, Integrated management of cogeneration plants and district heating networks, Appl. Energy. 97 (2012) 590-600.

[63] M. Houwing, R.R. Negenborn, B. De Schutter, Demand Response With Micro-CHP Systems, Proc. IEEE. 99 (2011) $200-213$.

[64] G. Papaefthymiou, B. Hasche, C. Nabe, Potential of Heat Pumps for Demand Side Management and Wind Power Integration in the German Electricity Market, IEEE Trans. Sustain. Energy. 3 (2012) 636-642.

[65] E. Carpaneto, G. Chicco, P. Mancarella, A. Russo, Cogeneration planning under uncertainty Part I: Multiple time frame approach, Appl. Energy. 88 (2011) 1059-1067.

[66] E. Carpaneto, G. Chicco, P. Mancarella, A. Russo, Cogeneration planning under uncertainty. Part II: Decision theory-based assessment of planning alternatives, Appl. Energy. 88 (2011) 1075-1083.

[67] K. Siler-Evans, M.G. Morgan, I.L. Azevedo, Distributed cogeneration for commercial buildings: Can we make the economics work?, Energy Policy. 42 (2012) 580-590.

[68] Department of Energy\&Climate Change, Digest of United Kingdom Energy Statistics 2013, 2013.

[69] A.D. Hawkes, M.A. Leach, On policy instruments for support of micro combined heat and power, Energy Policy. 36 (2008) 29732982.

[70] A.D. Hawkes, Estimating marginal CO2 emissions rates for national electricity systems, Energy Policy. 38 (2010) $5977-5987$.

[71] DECC, Fuel Mix Disclosure data table, (2012).

[72] A.F.M. for Transport, Feeding biogas into the Austrian natural gas grid, 2006.

[73] T.K. Jensen, Biogas to the natural gas grid, 2010.

[74] National Grid, The potential for Renewable Gas in the UK, 2009.

[75] Department of Energy \& Clima Change, Biomethane into the Gas Network: A Guide for Producers, 2009.

[76] Renewable Heat Incentive, (www.biogas-info.co.uk/index.php/incentives-qa.html).

[77] R. Yokoyama, T. Wakui, J. Kamakari, K. Takemura, Performance analysis of a CO2 heat pump water heating system under a daily change in a standardized demand, Energy. 35 (2010) 718-728. 